\title{
Diferencias regionales en la conducta tecnológica de las empresas manufactureras mexicanas: el caso de Guanajuato
}

\author{
SALVADOR ESTRADA*
}

\begin{abstract}
This paper gives an account of the technological behaviour of manufacturing enterprises in Mexico, with emphasis on the empirical descriptive work provided by the official data, as well as on the academic research in the field of innovation economy and technological change. We show that the Mexican manufacturing enterprises have a low technological dynamism, with scarce technological activities of their own whose main objectives are the production expansion and the increasing improvement of the productive processes. These activities rely mainly on the accumulation of internal know-how, in particular by engineers, and do not relate to other market or institutional agents. At a regional level, there are also a number of disparities as exemplified by the case of the State of Guanajuato. In this paper, we present the result of a survey on innovation of the manufacturing enterprises located in the above mentioned State.
\end{abstract}

Keywords: description, survey, innovation.

\section{Resumen}

En este artículo se detalla la conducta tecnológica de las empresas manufactureras en México con énfasis en el trabajo empírico descriptivo contenido en los datos oficiales, así como en la investigación académica en el campo de la economía de la innovación y del cambio técnico. Se muestra que las empresas manufactureras mexicanas tienen un bajo dinamismo tecnológico, con escasas actividades tecnológicas propias cuyas principales vertientes son la expansión de la producción y la mejora incremental de los procesos productivos. Estas actividades descansan en la acumulación de know how interno, en particular de los ingenieros, y tienen muy pocas relaciones con otros agentes de mercado o institucionales. Regionalmente también existen muchas disparidades, como ejemplifica el caso del estado de Guanajuato. En este trabajo se presentan los resultados de una encuesta de innovación en las empresas manufactureras localizadas en dicha entidad.

Palabras clave: descripción, encuesta, innovación.

* Centro de Investigaciones Humanísticas, Universidad de Guanajuato. Correo-e: salvador.estrada@gmail.com. 


\section{Introducción}

Al conjunto de decisiones referidas a la adquisición y generación de tecnología, así como a las actividades desarrolladas para incorporarla en los procesos productivos de las empresas, le llamaremos conducta tecnológica. Cabe destacar que esta conducta está constreñida al comportamiento económico de la empresa; esto es, está encaminada a satisfacer una necesidad en el mercado manteniendo el principio de racionalidad limitada de los agentes económicos. Entonces, la mejor solución no es precisamente la técnica, en términos tecnológicos, sino la que resulte viable económicamente en circunstancias particulares delimitadas por un entorno institucional y competitivo, además de un contexto específico de recursos restringidos (cualitativa y cuantitativamente).

Así, esta conducta está influida por diversos factores internos y externos a la empresa, como el grado de especificidad del conocimiento asociado a la tecnología y su sustento material, así como a las prestaciones y usos precedentes de los productos por fabricar. Ambos tipos de factores pueden asociarse con procesos y mercados experimentados o no con anterioridad. Es preciso enfatizar el hecho de que en este planteamiento se rebasa el marco convencional que equipara conocimiento a información, puesto que se considera la dificultad de apropiarse de la parte tácita del conocimiento.

Se ha tendido a operacionalizar la conducta tecnológica en las empresas mediante el gasto en investigación y desarrollo (I+D); sin embargo, la economía de la innovación ha desarrollado trabajos de fundamento empírico donde se visualiza que dicha conducta es un proceso complejo que involucra actividades tanto dentro como fuera de la firma, y que difícilmente puede ser caracterizada por una variable imputable a la empresa o al mercado.

Así que para expresar la conducta tecnológica hemos recurrido a un vector de variables que recogen la adquisición de tecnologías externas, el esfuerzo interno de adaptación e innovación tecnológicas, y el resultado innovador proyectado en la política de productos. La descripción que hacemos intenta recoger la conducta tecnológica del establecimiento medio en el país, para lo cual nos auxiliemos de las estadísticas oficiales y de algunos estudios empíricos que examinan algunas características de la conducta aquí propuesta.

A continuación hacemos una descripción de la conducta tecnológica en Guanajuato, donde se localizan las empresas sujetas a estudio. El conjunto de datos utilizados en este artículo provie- 
ne de la Encuesta sobre investigación y desarrollo experimental, vinculación, tecnología e innovación en el estado de Guanajuato $1999,{ }^{1}$ realizada por el Instituto Nacional de Estadística, Geografía e Informática (INEGI) y el Consejo de Ciencia y Tecnología del Estado de Guanajuato (Concyteg). ${ }^{2}$

La forma en que se presenta la información es por bloques de dimensiones, a saber: la estructura, la adquisición de tecnologías externas, el esfuerzo interno de adaptación e innovación tecnológicas, y el resultado innovador proyectado en la política de productos. Cada sección se inicia con una exposición sobre la situación nacional y, en el caso, algún referente relevante (p. e. Iberoamérica o algún estado de la República Mexicana), y después se describen las condiciones encontradas para el caso de estudio: la población de empresas manufactureras de Guanajuato. Se muestra que existe una gran variación respecto a los datos de las fuentes nacionales.

La interpretación de los diversos indicadores se hace en un contexto más amplio que intenta capturar la visión sistémica del enfoque macro e institucional del sistema nacional de innovación, para lo cual se presenta a continuación una breve descripción del contexto mexicano en que se desarrollan los establecimientos objeto de este estudio.

\section{El contexto mexicano}

Las reformas estructurales en México, que se iniciaron a fines de la década de los ochenta, plantearon enormes desafíos competitivos para las empresas al enfrentar la liberalización comercial, la privatización de grandes empresas paraestatales y la desregulación. Dichas reformas han resultado en un cambio en la especialización productiva nacional basado en un proceso de destrucción de empresas, cadenas productivas y competencias técnicas locales que dio paso al fortalecimiento de un grupo de empresas -surgido en el periodo de sustitución de importaciones- en el que se gestaron nuevas capacidades de organización de la producción que posibilitaron su integración al sistema productivo global (Cimoli, 2001); asimismo con base en el surgi-

${ }^{1}$ En el anexo se presentan los antecedentes, el marco muestral, el diseño estadístico, el diseño del cuestionario, el desarrollo de la encuesta y los niveles de respuesta y representatividad obtenidos.

${ }^{2}$ El autor de este artículo participó en el diseño y levantamiento de esta encuesta cuando fungió como coordinador de Estudios y Política Científica y Tecnológica del Concyteg. 
miento de un nuevo actor, constituido por capitales multinacionales, dedicado a maquilar bienes intensivos en tecnología y prendas de vestir destinados a los mercados de exportación o al comercio intraindustrial con grandes corporaciones globales.

El liderazgo de este grupo de empresas, conformado por multinacionales y oligopolios locales, también ha propiciado una desespecialización en bienes de capital que se ha traducido en una gran dependencia de la importación de tecnologías foráneas. De aquí que los esfuerzos tecnológicos locales han girado en torno a la modernización asentada en innovaciones de proceso, mas no en la renovación de capital fijo (Cimoli, 2000).

Además existe una rigidez estructural en el sistema productivo para la aparición de nuevas industrias líderes. Una buena parte del producto interno bruto (PIB) manufacturero proviene de bienes tradicionales y sectores intensivos en escala (alimentos y bebidas, acero, vidrio, minerales, cementos, petroquímica básica) (Dussel Petters, 1997). Estos sectores están dominados por el capital nacional, mientras que las empresas penetradas por capital multinacional se especializan en el sector automotriz y de ensamblaje de productos eléctricos y electrónicos.

Si se evalúa el desempeño industrial como un índice del valor añadido manufacturero y el esfuerzo exportador, México encabeza las economías latinoamericanas. En el periodo 1985-1998, la tasa de crecimiento del valor añadido $(6.2 \%)$ ha estado ligeramente por encima del promedio regional latinoamericano (5.9\%), pero más alejada del promedio de las economías del Este asiático (9.3\%), las más dinámicas en el ámbito de los países en desarrollo. Las exportaciones manufactureras han venido incrementándose a una tasa de $21.4 \%$ desde 1985 . El contenido tecnológico de estas exportaciones también se ha acrecentado, llega a representar un porcentaje muy considerable en el total de las exportaciones manufactureras mexicanas. Este porcentaje es uno de los más altos en el mundo sólo detrás de los de Japón, Filipinas y Singapur (UNIDO, 2002).

Gran parte de este desempeño se ha debido a la actividad de las empresas trasnacionales, en particular a las industrias maquiladoras de exportación localizadas cerca de la frontera con Estados Unidos. Esta localización internacional de actividades en el ámbito local se ha traducido en grandes flujos de inversión extranjera directa. De esta forma, una importante proporción del progreso tecnológico se ha hecho depender de la transferencia de tecnología internalizada a las plantas asociadas con dichas 
corporaciones. Sin embargo, son muy débiles los vínculos que estas organizaciones establecen con el entorno local, por lo que disminuyen los efectos de la difusión internacional de tecnología en la economía.

Por otra parte, la industria manufacturera mexicana invierte poco en actividades de I+D. El cambio estructural ha mermado la escasa capacidad de inversión. Entre 1985 y 1998, el gasto empresarial en I+D como proporción del PIB se ha reducido anualmente a una tasa cercana a $8 \%$ (UNIDO, 2002). El gasto está orientado básicamente tanto a la modernización y reorganización de los procesos productivos como a aumentar la calidad de los productos. Asimismo las actividades de I+D están concentradas en unos pocos sectores: automóviles, vidrio, cemento, máquinas de oficina y equipo electrónico. Se financian y ejecutan con un sesgo hacia adentro, por lo que las externalidades hacia el entorno, con clientes o proveedores, centros de investigación y universidades, son más bien escasas.

En consecuencia, la empresa considera como su principal fuente de aprendizaje tecnológico al capital humano. Sin embargo, respecto a otros países México presenta un acervo de personal científico y tecnológico pequeño, además de que la matriculación en los niveles secundario y terciario, por grupo de edad, es claramente inferior. De hecho, un estudio reciente destaca que este indicador se ha deteriorado (UNIDO, 2002).

De esta forma, existe un desempate en el desempeño exportador y el industrial, que se refleja en la conducta tecnológica. Se espera, no obstante, que el análisis microeconómico de la conducta dé pautas para identificar capacidades innovativas que permitirían sustentar la competitividad futura previendo la erosión progresiva de los soportes actuales: bajos costes laborales, ventajas localizacionales y preferencias contractuales por integración al Tratado de Libre Comercio de América del Norte (TLCAN).

\section{Diferencias en la eficiencia productiva de las empresas}

Las empresas manufactureras en México han mostrado respuestas muy heterogéneas al reto de la globalización e integración comercial. En su estudio sobre la productividad de la industria mexicana, Brown y Domínguez (1999a) encontraron que existe una gran dispersión en los niveles de productividad entre los sectores de actividad económica, que las empresas de menor tamaño presentan una brecha profunda respecto a las grandes, que la 
productividad aun antes de la apertura mostraba una tendencia creciente, y que las ganancias en este indicador no están asociadas con la reducción del empleo sino con el crecimiento del valor agregado y con el uso intensivo del capital.

En el periodo 1991-1998, de acuerdo con los datos de la Encuesta nacional de empleo, salarios, tecnología y capacitación en el sector manufacturero (ENESTYC), la productividad de la industria manufacturera no maquiladora se incrementó en más de 10\%. Los sectores que encabezaron estas ganancias fueron la industria automotriz y el segmento de industrias de alta tecnología (equipo de comunicaciones, electrónica y química fina). Casanueva y Márquez (2003) presentan un modelo econométrico que muestra que durante el citado periodo las ganancias en productividad estuvieron asociadas con el nivel educativo de los empleados.

De acuerdo con estudios de la productividad según el establecimiento (Brown y Domínguez, 1999b), existe evidencia de que los establecimientos de alta productividad presentan diferencias significativas en cuanto a su tamaño. Sólo el perfil de los grandes establecimientos de alta productividad se asocia con el atributo exportador, y tienen éstos un nicho de especialización en los sectores intensivos en escala y los dominados por los proveedores. Tanto para las pequeñas como para las grandes empresas, la alta productividad estuvo asociada con la participación de capital extranjero, ${ }^{3}$ el uso intensivo de tecnologías duras y mano de obra especializada.

Regionalmente también se encuentran disparidades importantes en los niveles de productividad, e incluso en el tiempo, pese a que las regiones aumentaron sus índices de productividad tendieron a incrementar sus divergencias. Las causas de semejante comportamiento se atribuyen a los cambios estructurales (políticas de ajuste y apertura), flujos de inversión extranjera hacia ciertos sectores estratégicos y también a las tendencias históricas de corto plazo de cada región. ${ }^{4}$ Cabe destacar que las únicas entidades que logran converger son las que alojan los principales centros industriales del país: Distrito Federal, Nuevo León, Jalisco y Estado de México (Mendoza, 1999). Este efecto de aglo-

${ }^{3}$ La intensidad del capital extranjero parece influir positivamente en el crecimiento de la productividad de los establecimientos, de acuerdo con el estudio de Blomström y Wolff (1994) sobre convergencia en la productividad entre firmas multinacionales y empresas locales en México.

${ }^{4}$ De la Garza et al. (1998) sugieren que las diferencias regionales en la productividad pueden deberse a diferencias en los mercados de trabajo y patrones de negociación colectiva, así como a las particularidades de la gestión de recursos humanos. 
meración afecta las condiciones ambientales en las que opera la empresa, tales como la infraestructura, la magnitud de los mercados, la provisión de energía y la capacidad de los servicios educativos y financieros (Hernández Laos, 1985).

\section{Diferencias en las características estructurales de las empresas}

\subsection{México}

El tamaño medio de una empresa manufacturera en México, de acuerdo con el Censo Industrial de 1999, es de 12 empleados (INEGI, 2000). Las empresas grandes, que constituyen poco menos de $1 \%$, contribuyen con $44 \%$ del empleo y $62 \%$ de la producción. Con esta información se realiza el diseño estadístico de la Encuesta Industrial Anual -que incorpora con certeza establecimientos mayores de cien empleados y con participación importante en el valor añadido bruto, además de que sólo tiene representatividad nacional y para las entidades que mayor participación tienen en el valor bruto de la producción, a saber: Distrito Federal, Nuevo León, Jalisco, Estado de México y Puebla-, la cual refleja que el tamaño de la empresa manufacturera media es de 240 empleados para el periodo 1997-2000.

La estructura de edades de las empresas en una muestra de establecimientos manufactureros revela que más de 50\% se encontraba en el rango de 4 a 15 años y casi 30\% eran más jóvenes (ENESTYC, 1999), lo cual habla de un ambiente turbulento de competencia donde la baza competitiva es la supervivencia. ${ }^{5}$ Cálculos propios con base en promedios y ponderaciones para los estratos y casos, respectivamente, llevan a plantear que la edad media poblacional debe ser del orden de 10 años.

En lo relativo a la pertenencia a grupos nacionales o extranjeros, la gran mayoría de empresas manufactureras operan de for-

${ }^{5}$ Un estudio de la evolución del empleo en México demuestra que la talla del establecimiento ha venido reduciéndose y que esta reducción ha estado acompañada de una disminución en la edad promedio (Rendón y Salas, "Evolución del empleo en México 1895-1980", Estudios Demográficos y Urbanos, 2 (2), 1987, citado en De la Garza et al., 1998: 97). Sin embargo, en el sector exportador la evolución de las características de los establecimientos maquiladores indica que el tamaño medio del establecimiento ha venido aumentado desde los años ochenta. Para el periodo 19801985, el establecimiento promedio tenía una talla de 236 empleados, la cual se incrementó durante la época de la transición hacia la apertura hasta 274 empleados, para llegar a casi 300 empleados, en promedio, con la economía mexicana inserta en el TLCAN (1994-1996) (Expansión, 1997). 
ma independiente, puesto que sólo 6\% manifestó su condición filial o subsidiaria (ENESTyC, 1999). Lo anterior concuerda con la distribución hallada en la segunda Encuesta Nacional de Innovación (Conacyt, 2003), donde se afirma que 90\% de las empresas manufactureras presentan una composición de capital mayoritariamente nacional. La participación promedio del capital extranjero en la estructura de los establecimientos manufactureros es de 17\% (ENESTYC, 1999); sobresale en los sectores de productos metálicos, maquinaria y equipos (40\%), y sustancias químicas, productos derivados del carbón, de hule y plástico (31\%), y con débil presencia en el sector de productos minerales no metálicos (3\%). Respecto al tamaño, parece que la participación de empresas con capital mayoritariamente foráneo se incrementa de acuerdo con esta dimensión (Conacyt, 2003).

Para la industria mexicana se ha elaborado un perfil tecnológico inspirado en la clasificación de patrones sectoriales del cambio tecnológico elaborada por Pavitt (1984) para el Reino Unido. Dutrénit y Capdevielle (1993) realizan una estimación empírica de los sectores manufactureros a cuatro dígitos de desagregación -prácticamente, en el nivel de productos- a partir de las tipificaciones existentes para el Reino Unido (Pavitt, 1984) e Italia (Soru, 1986), la cual es validada mediante la cuantificación de la importancia relativa en la explotación de tres tipos de tecnología: dura (aproximada por la relación capital-trabajo), blanda (utilizando el gasto en patentes, marcas y royalties como proxy) y de habilidades (analizando las remuneraciones medias).

Los sectores dominados por el proveedor presentan un bajo requerimiento de capital y escasas habilidades de los trabajadores, y sus gastos en royalties están sesgados hacia la adquisición de marcas, además de que su cuantía está por debajo del promedio manufacturero. Los proveedores especializados también tienen un bajo requerimiento de capital dado que los procesos productivos que utilizan no son continuos ni de gran escala, las habilidades de la mano de obra están por encima del promedio manufacturero y demandan altos niveles de tecnología blanda traducidos en pagos por el uso de patentes. Por su parte, los sectores intensivos en escala presentan los más altos niveles de tecnología dura y de habilidades dado que son los más mecanizados y requieren destrezas calificadas para la explotación de procesos continuos -si bien los altos salarios pueden deberse a un mayor poder monopólico de estas empresas y del grado de sindicalización de la mano de obra-, y su demanda de tecnología blanda 
está por arriba del promedio. El sector basado en ciencia exige una alta calificación, además de ser el principal demandante de tecnologías blandas basadas en conocimientos tácitos.

La conclusión de esto es que la clasificación de Pavitt es útil para determinar diferenciales de capacidades y desempeño tecnológico dentro de la industria, mexicana aunque debe tomarse como una primera aproximación para identificar patrones dado que algunas actividades no se corresponden totalmente con las características enunciadas en dichos patrones. ${ }^{6}$

La mayor participación de los sectores maduros (los dominados por el proveedor y los intensivos en escala) en el producto y el empleo es una característica muy marcada de la industria manufacturera mexicana; contribuyen con algo más de 80\%. Desde finales de los años ochenta (periodo de transición hacia la apertura e integración comercial) se ha observado un ligero crecimiento de los sectores basados en la ciencia y una caída en el sector de proveedores especializados (Capdevielle, Corona y Hernández, 1998). En relación con las vinculaciones técnicas entre proveedores y usuarios, el mayor intercambio ocurre entre empresas de un mismo sector. El eslabón más débil y escaso se presenta entre las industrias en los sectores avanzados; esto es, los intensivos en ciencia y los oferentes especializados (Corona y Hernández, 1999; Unger, 2001a).

Regionalmente se observan diferentes niveles de industrialización y grados de modernización. Unger y Saldaña (1999) argumentan que existen diferencias significativas entre los estados del norte, del centro y del sur de México. También se observan grandes diferencias entre las subzonas de cada estado. La modernización industrial se aproxima con indicadores de productividad, intensidad de capital (mecanización), salario industrial promedio y grados de transformación industrial frente a la importancia de las materias primas. Respecto a la participación de las diferentes industrias, de acuerdo con los patrones sectoriales del cambio tecnológico, las estructuras regionales tienden a reproducir el esquema nacional (Unger, 2001b). Las regiones más diversificadas

\footnotetext{
${ }^{6}$ Los propios autores reconocen las limitaciones de las variables utilizadas para intentar medir el capital, la tecnología utilizada en la producción y el nivel de habilidades de los trabajadores, pero es la información disponible en los censos oficiales. Si bien se utiliza la máxima desagregación posible en el análisis, valdría recordar que el trabajo de Pavitt (1984) se basa en el estudio de la conducta innovadora al nivel de la empresa, y que entre las regularidades encontradas estaba la pertenencia a un conjunto de actividades manufactureras determinadas, por lo que la lógica de la taxonomía es de los individuos hacia las actividades y no al revés.
} 
(atendiendo a una participación de los sectores basados en ciencia y de oferentes especializados mayor al promedio nacional) se encuentran entre los estados cuya productividad converge y de mayor participación en el producto nacional (Distrito Federal, Nuevo León, Jalisco, Estado de México y Puebla), como también entre los estados de la frontera norte (Baja California, Sonora, Chihuahua, Tamaulipas) y algunos del centro (Morelos, Tlaxcala, Querétaro, Aguascalientes y Guanajuato).

\subsection{Guanajuato}

El perfil medio que se dibuja de la muestra estudiada, para el estado de Guanajuato, es de empresas de tamaño mediano (150 empleados). Las empresas micro (hasta 30 empleados), pequeñas (de 31 a 100 personas) y medianas (plantillas de entre 101 a 250 personas) representan poco menos de $85 \%$ de la población y realizan $55 \%$ de las ventas. Las empresas grandes (mayores a 250 empleados) emplean a $65 \%$ del personal en el total de la muestra. El capital extranjero, en promedio, participa en la propiedad con $6 \%$. Su importancia aumenta con los estratos de tamaño; es despreciable entre las micro, está en el orden de 7 a $8.5 \%$ entre las pequeñas y medianas empresas (pymes), hasta llegar a $15 \%$ en las grandes. La población de empresas tiene una edad media de 14 años y la experiencia media parece seguir una tendencia creciente de acuerdo con el estrato de tamaño.

Si estudiamos la muestra con la atención al periodo de fundación de las empresas, podemos distinguir tres grupos: aquellas empresas fundadas tras la crisis de 1994 y la entrada en vigor TLCAN (O NAFTA, por sus siglas en inglés) (32\%), las empresas nacidas durante la etapa de reformas estructurales y transición hacia la apertura (1985-1993) (30\%), y las que se iniciaron durante (o incluso antes de) la etapa de industrialización basada en importaciones (antes de 1984) (38\%). Las empresas de mayor antigüedad y que han sobrevivido a las diferentes crisis y modelos de industrialización tienen un tamaño promedio mayor, correspondiente al estrato grande, y les toca poco más de $42 \%$ del total de las ventas en la muestra. Las de mediana edad tienen en promedio un tamaño mediano, y las más jóvenes son, en media, de tamaño pequeño. Para dar una idea sobre la dinámica de competencia a la que se han visto sometidas, puede ser útil conocer la edad media de cada grupo. La edad media de las jóvenes es de tres años; la de las adultas, de 9.4, y la de las maduras, de 26.5. 
Si nos enfocamos a la estructura de propiedad, la gran mayoría de las empresas son independientes (88\%). El resto de la población se compone de empresas transnacionales (7\%) y pertenecientes a grupos nacionales (5\%). El tamaño medio de las independientes es mediano, mientras en las filiales es el grande. Las ventas y el empleo se concentran en las empresas independientes (poco más de 70\% en los totales de ambas variables), aunque en las ventas se destaca la participación de las empresas transnacionales, que contribuyen con $22 \%$. Las empresas con edad promedio menor son las pertenecientes a grupos transnacionales, y las más longevas son las de grupos nacionales.

Sectorialmente, ${ }^{7} 62 \%$ de empresas pertenece a sectores de baja tecnología (proveedores tradicionales de bienes intermedios y productores de bienes de consumo tradicional -prácticamente, la mitad de toda la muestra-), y el resto a sectores de tecnologías medias $^{8}(20 \%$ a proveedores especializados de bienes intermedios y de equipo, $15 \%$ están basados en ciencia y el 3\% restante son intensivos en escala y ensamblaje). Las empresas que pertenecen a los sectores de proveedores de bienes intermedios, tanto tradicionales como especializados, así como las que se ubican en los sectores basados en ciencia, tienen, en promedio, un tamaño pequeño. En el sector de productores tradicionales, la empresa promedio tiene un tamaño de mediana escala, mientras que la que se encuadra en el sector intensivo en escala y ensamblaje es de tamaño grande. El sector que concentra tanto las ventas como el empleo es el de bienes tradicionales. El capital transnacional tiene una importancia promedio mayor en el sector intensivo en escala y ensamblaje, seguido por el sector de proveedores intermedios especializados. Cabe destacar que el capital extranjero no tiene participación en ninguna empresa del sector proveedor tradicional de bienes intermedios. La experiencia media es mayor, también, en el sector intensivo en escala y ensamblaje.

7 Las empresas presentan una enorme variedad respecto a las fuentes de oportunidad tecnológica, así como a la tasa y dirección del cambio tecnológico. Así, no existen criterios unificados para asignar inequívocamente a las industrias a la clasificación de Pavitt (Laursen y Meliciani, 2000). Para el caso de Guanajuato se utiliza una variante basada en las regularidades empíricas de unidades negocios agregadas hasta sectores industriales (Archibugi et al., 1991) y la selección de empresas por consenso con criterios de oportunidad tecnológica (Buesa y Molero, 1996).

${ }^{8}$ En la muestra no hay empresas del sector de alta tecnología, salvo dos empresas del sector farmacéutico. Para una consulta sobre la correspondencia de las actividades económicas con la clasificación en patrones sectoriales e industriales de innovación, puede consultarse el anexo. 


\section{Diferencias en la conducta tecnológica de las empresas}

\subsection{Adquisición tecnológica (incorporada y no incorporada)}

\subsubsection{México}

En el ámbito nacional, la inversión anual en activos fijos correspondiente a maquinaria y equipo de producción es, en promedio, ligeramente inferior a $3 \%$ de los ingresos por ventas en la industria manufacturera mexicana (EIA, 2003). Durante la década de los años noventa, en promedio, 30\% de los establecimientos afirmaron haber adquirido maquinaria y equipo sobre una base trianual (ENESTyC, 1992, 1995 y 1999). Las razones para llevar a cabo esta inversión tuvieron que ver, principalmente, con la obtención de aumentos en la productividad y la mejora en la calidad de los productos. De acuerdo con las dos encuestas de innovación levantadas en México (Conacyt, 1999 y 2003), el rubro principal del gasto en actividades innovadoras -más de 60\%- se dedica a la compra de maquinaria y equipo. Los sectores que mayor proporción de su gasto innovador destinan a la maquinaria y equipo son: madera, papel, imprentas y publicaciones (95\%); muebles y otras manufacturas (81\%), y carbón, petróleo, energía nuclear, químicos y productos de caucho y plástico $(75 \%)$ (Conacyt, 2003).

En lo que atañe a los gastos en transferencia de tecnología, esto es, la compra de los derechos o licencia para la adquisición o explotación de diversos conocimientos no incorporados en la maquinaria y equipo, la intensidad del esfuerzo relativo a las ventas se cifra en poco más de $0.8 \%$ (EIA, 2003). Cuando se analiza este tipo de gasto a la luz del esfuerzo innovador, la adquisición de tecnología externa ligada a la innovación participa con $6 \%$ (Conacyt, 1999 y 2003). El sector de productos fabricados de metal es el que destina una proporción mayor (10\%), seguido de los sectores alimentos, bebidas y tabaco, y maquinaria, equipo, instrumentos y equipos de transporte (ambos con 9\%).

Las empresas manufactureras en México presentan un perfil característico de una dependencia casi total de insumos foráneos, en particular de origen extranjero, pero también provenientes de otras localidades nacionales. La evidencia apunta a que son muy escasas las vinculaciones con proveedores locales. De acuerdo con un estudio de De la Garza et al. (1998) sobre 
500 establecimientos en 14 zonas industriales del país, ${ }^{9}$ las relaciones entre empresas localizadas en una misma zona son escasas, incluso en la participación como demandante u oferente de maquila o subcontratación, ${ }^{10}$ además de que existe una gran dependencia de insumos importados.

La contratación de servicios tecnológicos es escasa. De acuerdo con la segunda Encuesta Nacional de Innovación (Conacyt, 2003), su importancia relativa en el total de gastos es como sigue: la consultoría y la asistencia técnica; la gestión de patentes, licencia y marcas, y, en un mismo nivel, los estudios de mercado así como la normalización y el control de la calidad. Las actividades que mayor interés relativo muestran por estos servicios son: el sector de muebles y otras manufacturas, por las consultorías; alimentos, bebidas y tabaco, tanto por la gestión de activos intangibles como por los estudios de mercado, y los productos minerales no metálicos, por la normalización y el control de calidad.

Estos servicios tecnológicos, sin embargo, no son muy apreciados como fuente de innovación por lo que se desprende de la evaluación de las empresas innovadoras, de las que sólo $12 \%$ considera altamente significativas a las empresas de consultoría. En este rubro, la fuente externa más apreciada son los clientes (61\%), las ferias y exposiciones (46\%), y los proveedores de equipos, materiales y componentes (44\%) (Conacyt, 2003).

En relación con las colaboraciones técnicas, sólo 5\% afirma haber realizado algún acuerdo de colaboración con otra empresa o institución en el periodo 1999-2000. El patrón de distribución de los socios no parece concentrarse de acuerdo con el número total de acuerdos celebrados. Nuevamente, la importancia relativa de las empresas de consultoría (14\%) se ve relegada por los proveedores de equipo, materiales y componentes (20\%), así como respecto a los clientes (16\%). Casi tres cuartas partes de

${ }^{9}$ Las cuales están ubicadas tanto en los estados que presentan convergencia en su productividad: Distrito Federal (Iztapalapa), Nuevo León (Monterrey) o Jalisco (Guadalajara), como en otros con diversas características, tales como alta industrialización (Puebla y Tlaxcala), alta participación de capital extranjero (Baja California-zonas de Mexicali y Tijuana-, Sonora -Hermosillo y Nogales-, Coahuila -Saltillo-, Aguascalientes y Querétaro), intervención pública importante (Veracruz -zonas de Córdoba y Veracruz-) o basados en actividades tradicionales (Yucatán, zona de Mérida).

${ }^{10}$ Ramírez (1998), en un estudio sobre la organización de las cadenas de aprovisionamiento de la industria maquiladora de exportación, comenta que en dichas cadenas sólo participa una centena de proveedores nacionales, de tamaño mediano y grande. Además, Katz y Stumpo (2001) señalan que son pocos los grandes conglomerados nacionales que han logrado incorporarse satisfactoriamente a este proceso. 
estos acuerdos fueron verificados con empresas localizadas en el territorio nacional (Conacyt, 2003).

Los centros de investigación y las universidades no parecen relevantes como fuentes de información y proveedores de servicios tecnológicos (Conacyt, 1999 y 2003). De acuerdo con la ENESTyc (1995), sólo 20\% de las empresas cuenta con algún tipo de relación con las instituciones de educación superior. No obstante, cabe destacar que las principales capacidades científicas y tecnológicas del país se han desarrollado en el sector académico. La generación y la acumulación de dichas capacidades han estado faltas de coordinación con las demandas e iniciativas en los sectores empresarial y gubernamental.

Sin embargo, existe evidencia de colaboración entre las empresas, las instituciones académicas y la administración pública (MEGCT, 1994; Álvarez, 1995; López-Martínez y Solleiro, 1995; ANuies, 1996; Estrada, 1997; Casalet y Casas, 1998; Coronado y Tapia, 1998; Casas et al., 2000). Se trata de procesos muy difíciles de documentar, lo cual se refleja en que la metodología de una gran parte de las investigaciones se basa en estudios de caso. Se constata que llegan a construirse redes por procesos interactivos desarrollados en el mediano y largo plazos. La colaboración se efectúa sobre una base regional -la cercanía geográfica permite focalizar los esfuerzos hacia un conjunto común de recursos naturales o actividades económicas (y sus externalidades derivadas) de interés local- o disciplinaria -la catálisis, los polímeros, los nuevos materiales o la ingeniería ambiental.

Regionalmente parece que existen localidades donde hay condiciones más favorables para el flujo de conocimientos entre diferentes agentes ${ }^{11}$ (Corona, 1997; Casas, 2001; Luna, en pren-

${ }^{11}$ De acuerdo con Corona (1997), la actividad de innovación en México tiende a concentrarse en ciertos polos: Cuernavaca (incluye también las ciudades de Cuautla y Temixco, en el estado de Morelos), Querétaro, Bajío (constituido por las principales ciudades del estado de Guanajuato), Ensenada-Tijuana-Mexicali (ciudades fronterizas en el estado de Baja California Norte) y en las grandes ciudades de Monterrey (capital del estado de Nuevo León, pero que abarca a la ciudad de Saltillo, en el estado de Coahuila), Guadalajara (incluye Zapopan, ubicada asimismo en el estado de Jalisco, y Colima, capital del estado vecino con el mismo nombre) y zona metropolitana de la Ciudad de México. Este autor utiliza el concepto de polos de innovación para referirse al espacio geográfico y a las relaciones entre empresas de base tecnológica, incubadoras de empresas, parques científicos, centros de investigación, universidades y un conjunto diverso de instituciones relacionadas con la información tecnológica, consultoría, firmas de ingeniería, y con la producción industrial y empresas de servicios, y mecanismos de financiamiento, que participan de alguna manera en las actividades de investigación y desarrollo y en los procesos de invención, innovación y difusión de nuevos productos, servicios y procesos productivos. 
sa). Entre dichas condiciones pueden citarse: una dotación importante de infraestructuras de investigación y una gran disponibilidad de recursos naturales -como lo ilustra el caso de los estados que rodean el Mar de Cortés, en la zona Noroeste del paíso una base industrial diversificada -en el caso de los estados del Bajío, en la zona Centro- o una industria altamente concentrada con empresas intensivas en escala -los estados de la frontera Noreste-. También habría que considerar la orientación de dichas infraestructuras de investigación y el proceso de industrialización seguido por la región.

En un plano de análisis más desagregado, se observa que la articulación de redes se fundamenta en relaciones informales y espontáneas, que pueden ser bilaterales -generalmente coordinadas por empresas grandes- o ampliadas - por los apoyos públicos y la participación de asociaciones de empresarios o productores u organismos internacionales-, así como en interacciones previas o sucesivas en el tiempo con diversos objetivos tales como la prestación de servicios técnicos especializados, la utilización de infraestructura, la formación de recursos humanos o la realización de proyectos de investigación. Los flujos de conocimiento se presentan por medio del intercambio personal cara-a-cara, la movilización de recursos humanos y los reportes técnicos (Estrada, 1997; Casas, 2003).

\subsubsection{Guanajuato}

Las empresas manufactureras para la muestra del estado de Guanajuato invirtieron, en promedio, $7 \%$ de sus ventas en la adquisición de maquinaria y equipo. Nuevamente se encuentran diferencias según las características de tamaño, edad, propiedad o sector. Las empresas que tuvieron un desempeño superior al promedio en el esfuerzo relativo a la adquisición de maquinaria y equipo fueron las micro y medianas, jóvenes, independientes, proveedoras -tanto tradicionales como especializadas- e intensivas en escala y ensamblaje. En términos absolutos, el gasto estuvo concentrado en el segmento de las grandes empresas.

El esfuerzo dedicado a la compra de licencias, know how, marcas, diseño, modelos y asistencia o estudios técnicos relativos a las ventas fue de $0.6 \%$. Las pymes hicieron un esfuerzo de alrededor de 1\%. Las empresas nacidas tras el periodo de sustitución de importaciones también presentan cifras superiores a la media. Sectorialmente, sólo los productores de bienes de consu- 
mo tradicional mostraron marcas superiores al promedio. El gasto se concentró en las pequeñas empresas y los proveedores especializados.

El 23\% de las empresas manufactureras analizadas en esta investigación utilizó servicios tecnológicos. Esta variable refleja la condición de usuario de agentes nacionales o foráneos, sean universidades, centros de investigación, empresas o agencias públicas, para proveerse de estudios técnicos, de ingeniería o consultoría, asistencia técnica, patentes, información tecnológica y comercial, así como para normalizar sus procesos o productos o introducir sistemas de calidad además de la intensidad de uso frecuente. Menos de 4\% declaró el uso regular de estos servicios. Prácticamente $10 \%$ de las empresas demandó estudios técnicos, de ingeniería o consultoría, asistencia técnica o licencias; otro 10\%, servicios de información tecnológica y comercial, normalización y calidad. Sólo 2\% utilizó ambos grupos de servicios. Las pymes (35\%), las de mediana edad (29\%) y las productoras de bienes de consumo (28\%) concentraron la demanda de servicios tecnológicos externos.

\subsection{Esfuerzo tecnológico (adaptativo-innovativo)}

El esfuerzo de innovación se mide por los insumos registrados en la contabilidad de gestión. La intensidad con que se comprometen recursos para estas tareas refleja las expectativas formadas en torno a un potencial innovador, pero no proporciona información sobre la eficiencia de estos gastos. Así, los ratios respecto a las ventas brindan un enfoque interpretativo sobre la toma de decisiones pasadas, la estrategia, la organización y los conflictos relativos a la conducta tecnológica de la firma.

En las economías latinoamericanas, históricamente, la principal fuente de adquisición de tecnología ha sido el abastecimiento internacional (Katz, 1976; Jaramillo et al., 2000). Sin embargo, la actividad inventiva endógena no puede suponerse nula, sino que es cualitativamente diferente: subsidiaria, adaptativa y dirigida a la obtención de mejoras marginales o adecuaciones al medio local de diseños. Dadas estas dos características, la importancia de los flujos externos y el sesgo adaptativo de la I+D, el análisis del esfuerzo tecnológico debe ampliarse y complementarse con el estudio de la actividad de ingeniería. El personal de producción e ingeniería realiza tareas de adaptación de procesos, equi- 
pos y partes que constituyen una buena parte del esfuerzo innovador de las empresas (Arvanitis y Villavicencio, 1998).

\subsubsection{México}

En México, la noción de I+D entre los empresarios no está establecida con claridad; se asocia con resolver problemas de producción o programación de nuevas actividades o inversiones y trabajos rutinarios de control de calidad, como lo ilustra un estudio en la industria alimentaria (Unger, y Márquez 1981). Una investigación reciente (Pacheco Salazar et al., 2003) sobre la percepción empresarial de las actividades científicas y tecnológicas muestra que no existe una idea clara de la rentabilidad de la I+D por lo que hay un escaso control contable y administrativo sobre este gasto. En cuanto a su expresión en la mano de obra, se trata como una actividad esporádica, puesto que no existe personal única y exclusivamente dedicado a estas tareas.

La innovación en general y el diseño industrial en particular también han sido actividades sujetas a indagación en la percepción empresarial. Una encuesta realizada entre 300 gerentes y directores de pymes manufactureras (Frías Peña et al., 2003) sugiere que menos de $50 \%$ asocia la innovación con la novedad y la mejora. Más de la mitad la asocia con el producto, principalmente con la ampliación de la línea de productos y, en menor medida, con su reemplazo. En lo que se refiere al diseño, se asocia más con la apariencia que con el proceso. Poco menos de un tercio asoció el diseño industrial con el desarrollo de nuevos productos, y tan sólo 10\% lo asoció con los procesos de manufactura.

Los datos empíricos de la segunda Encuesta Nacional de Innovación reflejan que 13 de cada 100 empresas manufactureras realizan actividades de investigación y desarrollo tecnológico, ${ }^{12}$ y que sólo una de aquéllas no organiza formalmente dichas actividades. Conforme aumenta el tamaño de las empresas, la realización de estas actividades se intensifica. Los sectores donde la actividad de I+D aparece más frecuentemente son el de carbón, petróleo, energía nuclear, químicos, productos de caucho y plástico (22\%), y el de maquinaria, equipo, instrumentos y equipo de

${ }^{12}$ Estos datos son para el periodo 1999-2000; si se contrastan con los resultados de la ENESTyC (1999) para el periodo 1997-1998, el porcentaje de empresas con actividad de I+D es de 7\%. De lo anterior puede interpretarse que la práctica de esta actividad se ha disparado prácticamente al doble en la industria manufacturera, o que las estimaciones presentan un rango de dispersión muy amplio. 
transporte además del de alimentos, bebidas y tabaco; ambos comparten 19\%. Esta actividad tiene una fuerte orientación intramuros, puesto que menos de $10 \%$ se contrata fuera de la empresa. Las empresas grandes contribuyen con más de un tercio del gasto industrial (Conacyt, 2003). ${ }^{13}$

La intensidad del esfuerzo promedio en $\mathrm{I}+\mathrm{D}$ en lo que toca a los ingresos es poco menos de 0.7\%. Durante el periodo de 1989 a 1998, la intensidad ha fluctuado entre 0.5 y $1 \%$. Es interesante destacar el sobresaliente desempeño de las empresas micro y pequeñas en los dos últimos años relevados. El sector que relativamente destina mayores recursos $\mathrm{a} I+\mathrm{D}$ es el de industrias y productos de la madera (2\%). Le siguen, en orden decreciente, los sectores de papel, imprentas y editoriales (1.5\%), y sustancias químicas, productos de carbón, hule y plástico (0.7\%). Cabe destacar que durante el periodo 1989-1998, algunos sectores han disminuido su importancia relativa, como el de productos metálicos, maquinaria y equipo -respecto al último año-, y el de minerales no metálicos y alimentos, bebidas y tabaco -tras la apertura e integración económicas- (ENESTyC, 1992, 1995 y 1999).

Los principales objetivos de este gasto son: a) el mejoramiento de los procesos productivos y la calidad de los productos $(73 \%$ califican a este objetivo como altamente significativo); $b$ ) el diseño de nuevos productos ( $45 \%$ de las menciones), y c) la adaptación de maquinaria y equipo (24\% de las respuestas) (ENESTyc, 1995).

Las fuentes de información tecnológica e innovación más importantes para las empresas mexicanas están dentro de ellas mismas (Arvanitis y Villavicencio, 1998; López-Leyva, 2003). El desarrollo y la modificación de productos y procesos se hacen mayoritariamente por cuenta propia. El departamento de producción, y el de mercadotecnia e ingeniería, en ese orden, son calificados por las empresas innovadoras como las fuentes de información significativamente más importantes (Conacyt, 1999 y 2003). Existe evidencia de que las empresas manufactureras, en general, prefieren las fuentes internas a las externas, y que consideran la experiencia, el conocimiento y las habilidades de sus ingenieros, técnicos y obreros como la fuente más relevante de innovación (Corona y Hernández, 1999).

\footnotetext{
${ }^{13}$ Nuevamente, si estos datos se contrastan con los de la ENESTyc (1999), el sector líder es el mismo (con 30\%), pero los que siguen difieren; para esta fuente, son los sectores de industrias metálicas básicas (20\%) y el de madera, papel, imprentas y editoriales (9\%). Aunque el sector de productos de metal, maquinaria y equipo sigue destacándose (9\%).
} 
Entre las empresas manufactureras, menos de una quinta parte cuenta con una unidad formal de ingeniería. Los sectores que están por encima de esta proporción son el de maquinaria, equipo, instrumentos y equipo de transporte (con poco menos de un tercio de las empresas), y el de carbón, petróleo, energía nuclear, químicos, productos de caucho y plástico (con poco menos de una cuarta parte). Se cuenta con siete personas ocupadas en actividades de ingeniería por cada millar de empleados en el sector manufacturero. El sector con mejor desempeño es el de maquinaria, equipo, instrumentos y equipos de transporte, que cuenta con una por cada cien (Conacyt, 2003).

Además del gasto en investigación y desarrollo, es de interés observar el esfuerzo en otras actividades innovadoras tales como el diseño industrial y otras actividades de arranque de la producción, la capacitación y el lanzamiento al mercado de innovaciones. Mientras que la I+D tuvo una participación de $9 \%$ en el total del gasto, las otras actividades muestran una importancia decreciente: de $9 \%$ en diseño a $3 \%$ en capacitación, pasando por $6 \%$ en mercadotecnia. Los sectores donde estas actividades muestran una mayor importancia relativa son: para la $\mathrm{I}+\mathrm{D}$, el de metales básicos (20\%), para el diseño, el de productos minerales no metálicos (29\%), y para la mercadotecnia y la capacitación, el de maquinaria, equipo, instrumentos y equipos de transporte (15 y 6\%, respectivamente) (Conacyt, 2003).

Para sopesar el esfuerzo nacional en capacitación y mercadotecnia para el desarrollo de nuevos productos no se cuenta con información específica sino sólo con algunas generalidades para la industria. En lo que se refiere a capacitación, alrededor de un tercio de las empresas la ha ofrecido para sus trabajadores durante la década de los años noventa; sin embargo, existe una ligera disminución respecto a los primeros años de ese lapso. En general, las horas promedio dedicadas a capacitación han aumentado, en particular en los sectores tradicionales, tanto de consumo como intermedios, y en la industria automotriz (Casanueva y Márquez, 2003).

En cuanto al gasto en publicidad y propaganda, en general, la industria manufacturera destina, en media, $1.6 \%$ de sus ventas (EIA, 2003). De acuerdo con los datos relativos al esfuerzo en publicidad respecto a los ingresos totales, la cifra disminuye hasta 0.89\%; destacan por encima de este nivel las empresas medianas y grandes y los sectores de papel y productos de papel, imprentas y 
editoriales (1.6\%); productos metálicos, maquinaria y equipo (1.3\%), y productos minerales no metálicos (1.1\%) (INEGI, 2000).

\subsubsection{Guanajuato}

En el estado de Guanajuato, la muestra de establecimientos reflejó una propensión de 7\% a realizar actividades de investigación y desarrollo; involucra formalmente $6 \%$. La propensión es menor entre los establecimientos micro (2\%), que aumenta hasta el $9 \%$ en las pymes y a $11 \%$ entre las grandes. Las empresas maduras y longevas muestran mayor propensión que las jóvenes. También las encuadradas en sectores de mayor contenido tecnológico (el basado en ciencias -8\%-, el de proveedores especializados -11\%- y el de intensivos en escala -16\%-) tienen un comportamiento superior al de los sectores tradicionales (bienes intermedios y de consumo).

En promedio, los establecimientos manufactureros destinan poco menos de $0.3 \%$ de sus ventas a las actividades de investigación y desarrollo. Se destacan, por la intensidad de sus esfuerzos, las pequeñas $(0.43 \%)$, los establecimientos maduros $(0.56 \%)$, los proveedores especializados $(0.76 \%)$ y los basados en ciencia $(0.33 \%)$. En lo que toca a los gastos totales, las pequeñas contribuyen con poco menos de $40 \%$ y las grandes con un tercio justo, con poco menos de dos tercios las maduras y las independientes con más de 75\%. Cabe destacar que una buena parte del gasto restante lo desarrollan empresas filiales de grupos nacionales (23\%). Más de la mitad del gasto se concentra en empresas ubicadas en el sector de proveedores especializados. Esta situación contrasta con la pequeña aportación del sector proveedor tradicional, que no llega ni siquiera a $1 \%$.

En la industria manufacturera guanajuatense encontramos aproximadamente cuatro personas con grado de ingeniero por cada centenar de empleados. Las empresas micro (con 6\%) y las pequeñas $(4 \%)$ son las que superan este promedio. De acuerdo con la edad, las empresas más jóvenes (5\%) y las más viejas (4\%) muestran un comportamiento superior a la media. Salvo en el sector de bienes de consumo tradicional, todas las empresas en el resto de los sectores tienen un desempeño por arriba del promedio; entre ellas destacan las encuadradas en los sectores intensivo en escala y ensamblaje (8\%) y de proveedores especializados (7\%). En lo que se refiere a su contribución absoluta, mientras las grandes ocupan a $64 \%$ de los ingenieros, las pequeñas emplean a 20\%. Por otra 
parte, las empresas más viejas son las que dan empleo a 48\% de estos profesionales. El $40 \%$ se emplea en empresas corporativas ( $24 \%$ en grupos nacionales, $16 \%$ en empresas trasnacionales [ETN]) y $60 \%$ en empresas independientes. El sector de bienes de consumo tradicional absorbe a $37 \%$ de ellos, y los productores intensivos en escala y ensamblaje, a $23 \%$.

La importancia relativa en el gasto innovador de las diferentes actividades sitúa al diseño muy por encima de la I+D (29 y $17 \%$ respectivamente), seguidos por el lanzamiento al mercado de nuevos productos (10\%) y, muy por detrás, por la capacitación relativa al desarrollo o mejora de productos y procesos $(0.8 \%)$. Los sectores donde estas actividades presentan una mayor participación son: el intensivo en ciencia -en diseño-, los proveedores especializados -en mercadotecnia- y los intensivos en escala y ensamblaje -en capacitación.

La intensidad media de estas actividades respecto a las ventas es la siguiente: $0.4 \%$ se dedica al diseño, menos de $0.2 \%$ al lanzamiento de nuevos productos y $0.02 \%$ a la capacitación relacionada con la introducción y desarrollo de nuevos productos. Las empresas que más se destacan por la intensidad de sus gastos son, en el diseño, las medianas, las jóvenes, las transnacionales y los productores de bienes de consumo tradicional; en el lanzamiento, las maduras, las transnacionales y los proveedores especializados; y, finalmente, en la capacitación, las pequeñas y las grandes, así como los productores intensivos en escala y ensamblaje. Los gastos en diseño y lanzamiento se concentran en las empresas independientes (64 y 53\% respectivamente). Sin embargo, los grupos corporativos -tanto nacionales como extranjeros- aportan poco menos de la mitad del gasto en lanzamiento, casi una cuarta parte cada uno. Tres cuartas partes del gasto en capacitación lo realizan las grandes empresas. Los sectores de consumo tradicional y el basado en ciencia aportan más de $80 \%$ al gasto total de diseño; los productores de bienes de consumo tradicional y proveedores especializados prácticamente aglutinan la totalidad del gasto en mercadotecnia, y con más de $90 \%$, los de consumo tradicional y los intensivos en escala copan el gasto en capacitación. Puede decirse que la participación en cada uno de estos gastos del sector de proveedores de bienes intermedios tradicionales es despreciable. 


\subsection{Dinamismo tecnológico e innovador}

Para la medición del resultado innovador se utilizan como indicadores tres variables: el número de productos nuevos introducidos en el mercado durante los últimos tres años, las ventas por productos mejorados y las ventas por el principal producto (o línea de productos).

En cuanto al calificativo de novedad de la gama de productos existe una polémica relacionada con el tipo y calidad de la novedad. Desde el punto de vista de la oferta, la Encuesta Comunitaria de Innovación (Comunity Innovation Survey, CIS) refiere a la cuestión tecnológica. En la Encuesta de Innovación de Canadá se prefiere dejarlo abierto, aunque se especifica excluir los atributos estéticos o cambios que incluyan pequeñas modificaciones. Desde el punto de vista del mercado, tanto la CIs como Statistics Canada piden que se considere a la novedad desde el punto de vista de la empresa o el mercado (Mohnen y Therrien, 2003).

En el caso de América Latina, Jorge Katz (1976) sugiere que sería mejor hablar de la puesta en marcha de diseños (de productos y procesos) inéditos en la historia productiva de la empresa. El tipo de output innovador que se obtiene, generalmente, son réplicas de productos y procesos existentes en otras empresas del mercado. La fuente de adquisición de la tecnología pasa por algún género de negociación contractual o bien de 'ingeniería inversa' que permite alcanzar dicho output.

Dado el carácter del esfuerzo innovador hacia la imitación y la adaptación en América Latina, consideramos que el impacto sobre las ventas más idóneo para el contexto es el de los productos mejorados. Sin embargo, con fines comparativos presentaremos las participaciones de los diferentes productos de acuerdo con su novedad en las ventas.

\subsubsection{México}

En México, según la segunda Encuesta Nacional de Innovación (Conacyt, 2003), la propensión innovadora -empresas que afirmaron que introdujeron algún producto y/o proceso tecnológicamente nuevo o significativamente mejorado en el bienio 1999-2001 sobre el total de empresas encuestadas- de la industria manufacturera fue de $28 \%$. De estas empresas autocalificadas como "innovadoras", 51\% introdujo novedades en el mercado nacional, 36\% en el mundo y sólo 13\% en la propia empresa. Aunque estos datos 
no son estrictamente comparables con los de la primera Encuesta Nacional de Innovación dado su sesgo hacia empresas grandes y potencialmente más innovadoras, la tendencia hacia el mercado nacional se mantiene en alrededor de 50\%, pero la novedad mundial parece sobrevaluada en un tercio, y en el ámbito de la empresa, subestimada en un medio. De las dos encuestas pueden sacarse dos cosas en claro: que las empresas pioneras en la innovación en el ámbito mundial son sólo un tercio del total de las empresas innovadoras previsto para la industria manufacturera mexicana, $y$ que entre las empresas innovadoras mexicanas predominan las innovaciones incrementales.

El número de productos nuevos introducidos en el periodo 1994-1996 fue de 4.3 productos por empresa manufacturera. Prestando atención sólo a las empresas autodefinidas como innovadoras, la marca mejora hasta llegar a 6.8 productos, que corresponda un desempeño superior al segmento de empresas grandes, con 8.4 productos nuevos introducidos en el periodo de referencia (Conacyt, 1999).

La cartera de productos según la intensidad en las ventas se distribuyó de la siguiente manera: $16 \%$ provino de productos nuevos, $21 \%$ por productos mejorados, y el resto por productos sin cambios. Un tercio de las ventas del sector de muebles y otras manufacturas se debió a productos nuevos, y un impacto cercano tuvieron en el sector de productos fabricados de metal. Esta actividad, a su vez, tuvo la mejor marca relativa a la participación en las ventas de los productos mejorados, la cual mostró magnitudes semejantes. Este desempeño también se presentó en el sector de madera, papel, imprentas y publicaciones. Los sectores más conservadores fueron el de alimentos, bebidas y tabacos, con poco menos de las tres cuartas partes de los ingresos por ventas provenientes de productos sin cambios; seguido por el de minerales no metálicos y el de carbón, petróleo, energía nuclear, químicos y productos de caucho y plástico, cada uno con $65 \%$ de sus ventas derivadas por este tipo de productos (Conacyt, 2003).

En la literatura consultada no se encontró información sobre las actividades de diversificación en las empresas. Sin embargo, en las fuentes sobre empresas maquiladoras se ha encontrado evidencia sobre el escalamiento industrial, esto es, el proceso por el que se verifica un ascenso en la complejidad de las actividades industriales. Así, el sistema productivo sufre transformaciones intersectoriales, intrasectoriales, en los roles económicos y las características de los productos (Gereffi y Tam, 1998). En 
las plantas maquiladoras del norte del país ha ocurrido una transformación de maquilas intensivas en mano de obra a intensivas en conocimiento; de la producción de commodities se ha pasado a la fabricación de bienes de alto valor agregado; de la actividad de ensamble se ha mudado a la manufactura y de aquí a la coordinación centralizada; se han emprendido nuevas y más complejas actividades (producción de componentes, maquinados, diseño e investigación y desarrollo, por ejemplo), además de elevarse sustancialmente el nivel tecnológico de los productos, sus estándares de calidad y las normas oficiales (Carrillo y Hualde, 1996; Lara Rivero, 1998; Buitelaar et al., 1999; Barajas Escamilla, 2000; Carrillo, 2001).

Dicho escalamiento industrial se ha acompañado de cambios organizacionales que han propiciado la generación y mejoramiento de capacidades laborales y técnicas, en particular las funciones de ingeniería se han ampliado y enriquecido (Hualde, 2001). La interpretación que se haga de este proceso y su dispersión en el resto de actividades debe considerar que: a) los estudios se han hecho en empresas en los sectores tecnológicos más dinámicos, tales como el electrónico y el automotriz, y b) los efectos están limitados de acuerdo con la posición en la cadena productiva; por ejemplo, entre más estandarizado sea un producto, menor será la red de aprovisionamiento (González-Aréchiga y Ramírez, 1989).

En el presente artículo, la idea que quiere establecerse es que la estandarización exige competencia técnica y mejora la capacidad endógena, y que es posible que la inversión en mejoras en calidad y productividad se haga más rentable que en el caso diversificado.

De acuerdo con un estudio de Ramírez y Unger (1996), las estrategias competitivas de empresas líderes en México suelen estar asociadas con la política de productos, la propiedad y la posición en el mercado. Así, estas asociaciones definen las siguientes situaciones:

- Las empresas que siguen una estrategia basada en la mejora de productos o en la introducción de nuevos materiales tienden a competir en mercados oligopólicos. Los grupos transnacionales, principalmente, aunque también algunos conglomerados nacionales, parecen seguir esta estrategia. En particular, en el sector intensivo en ciencia.

- Otro grupo de empresas, el cual explota sus ventajas en procesos y productos altamente específicos y compite, tam- 
bién, en mercados oligopolizados. Algunas empresas en los sectores intensivos en escala y ensamblaje son las que siguen este patrón.

- Las que basan su ventaja en reducción de costos compiten en estructuras menos oligopolizadas y buscan integrarse en los segmentos de la cadena de productos más estandarizados. Los grupos nacionales encuadrados en el sector de proveedores tradicionales parece que siguen esta conducta.

- Otros grupos de empresas constituyen complejos flexibles basados en la aplicación de sistemas organizacionales -las técnicas de justo a tiempo y control total de la calidadque favorecen la cooperación horizontal. Conforman el arquetipo la red de proveedores de la industria automotriz, los fabricantes de motores y artículos electrónicos y los productores de textiles y cuero.

\subsubsection{Guanajuato}

Las empresas guanajuatenses, en promedio, han introducido menos de un producto nuevo (0.89) durante el trienio de referencia. La intensidad de los productos nuevos en las ventas anuales es del orden de 4\%, mientras que la aportación de los productos mejorados es de 18\%. Del total de ventas, poco menos de las tres cuartas partes proviene de los ingresos por una sola línea o producto principal.

Las pymes introducen más de un producto nuevo y obtienen ingresos por las ventas de productos nuevos y mejorados mayores que el promedio. Las grandes presentan mayor intensidad en la ventas por productos mejorados que el resto de los estratos. Por otra parte, las pequeñas empresas dependen en mayor medida de los ingresos por la venta de su producto (o línea) principal. Las pequeñas concentran $40 \%$ de los productos nuevos y $45 \%$ de las ventas por este tipo de producto. Las empresas grandes participan de casi $70 \%$ de las ventas por productos mejorados y de $50 \%$ de las ventas por productos principales.

Las empresas más viejas ingresan 70\% de las ventas por productos nuevos, y las jóvenes, $75 \%$ de las ventas por productos mejorados. En promedio, la intensidad de las ventas por productos mejorados es mayor para las empresas de mediana edad.

Los grupos transnacionales parecen mucho más activos en la introducción de productos nuevos, pues durante el periodo de referencia introdujeron poco más de dos. La intensidad de los 
productos mejorados en sus ventas también resulta superior al promedio, pero las empresas de grupos nacionales doblan su eficiencia por la venta de este tipo de productos. Las filiales o subsidiarias de grupos nacionales obtienen, en media, $88 \%$ de sus ingresos por la venta de su producto principal.

Las empresas pertenecientes a los sectores productores de bienes de consumo tradicional fueron las únicas en lograr introducir más de un producto nuevo durante el periodo de referencia. También encabezaron el impacto en las ventas relativas a productos nuevos (5\%), mejorados (26\%) y principales $(79 \%)$. Casi una tercera parte de los ingresos manufactureros por la venta de productos nuevos se originaron el sector de productores de bienes de consumo. Una cuarta parte fue a parar al sector intensivo en ciencia, cuyas empresas tuvieron, en promedio, $4 \%$ de sus ventas originadas en este tipo de productos. Dos terceras partes de los ingresos totales por la venta de productos mejorados se obtuvieron en el sector de bienes de consumo tradicional, y un poco más de la cuarta parte se originó en el sector intensivo en escala y ensamblaje. Las empresas pertenecientes a este sector presentaron una intensidad promedio de $25 \%$.

\section{Diferencias entre la región analizada y el contexto del país}

El cambio estructural polarizó la competitividad hacia un conjunto de establecimientos y sectores líderes -ya fuertes durante la etapa de sustitución de importaciones-, los cuales concentran recursos, competencias técnicas y capacidades de producción. La proyección de sus competencias en el exterior no está asentada en una articulación productiva nacional ni hacia la demanda de insumos intermedios ni hacia la de bienes intensivos en capital y tecnología. Las estrategias de inserción de estos establecimientos en el sistema productivo global favorecen el comercio intraindustrial y desincentivan la demanda de insumos locales. La escasa capacidad técnica y el debilitamiento del sector de proveedores locales de tecnología ralentiza la difusión de los flujos internacionales y sesga los esfuerzos domésticos hacia el desarrollo de conocimientos genéricos, la reorganización productiva y el aumento de la calidad de los productos.

El resto del aparato productivo presenta respuestas muy heterogéneas al reto competitivo. Se revela que el tamaño juega un papel preponderante en las asimetrías productivas y en la capacidad de explotar economías de escala, del uso intensivo del ca- 
pital y de participar en actividades de mayor valor agregado. Otro factor clave en la competitividad es el capital humano. Pese a su escasez relativa, la evidencia apunta a que la mano de obra especializada y el nivel educativo de los empleados son responsables en buena medida de las ganancias en productividad.

La intensidad con la que participan los capitales extranjeros condiciona las estrategias competitivas, la organización de la producción, las fuentes de abastecimiento, el acceso a tecnologías y las prácticas de gestión de recursos humanos, pero también el potencial competitivo de empresas, sectores y regiones. Estos capitales tienden a seleccionar actividades de alto valor agregado, intensivas en capital y mano de obra no calificada.

Regionalmente también existen fuertes disparidades en la productividad por economías externas basadas en la infraestructura, los servicios financieros y los flujos de inversión extranjera, pero en particular por el mercado laboral: diferencias en la dotación de capital humano, patrones de negociación, gestión de recursos humanos y servicios educativos.

Es posible que esta panorámica de la industria manufacturera mexicana tenga un sesgo hacia estados de la república donde se concentran las economías externas, los sectores y los establecimientos líderes dada la escasa representación de un conjunto importante de estados intermedios. Así, se espera que el representante 'medio' de la industria manufacturera nacional difiera significativamente del promedio de un estado diferente de los que concentran los atributos especificados anteriormente. En general se tiene la expectativa de que las características estructurales y de la conducta tecnológica se ajusten hacia abajo. En la tabla 1 se presentan las dimensiones directamente comparables.

Para la región sujeto de estudio, el tamaño medio de la empresa es inferior; las empresas con capitales foráneos participan con menor intensidad en la propiedad; la compra de tecnología desincorporada es algo inferior; la propensión e intensidad de la actividad de I+D es de la mitad; la capacidad de introducción de productos nuevos se ve cuadriplicada, y el efecto en las ventas por productos nuevos es similar. Los efectos combinados de estas características parecen moderar la conducta exportadora y, como era de esperarse, la participación de empresas del caso de estudio en los mercados de exportación es inferior al caso nacional. 
Tabla 1

Diferencias entre empresas en los ámbitos nacional y estatal

\begin{tabular}{|c|c|c|c|}
\hline & Características & México & Guanajuato \\
\hline Estructura & $\begin{array}{l}\text { Tamaño (núm. de } \\
\text { empleados) } \\
\text { Edad (años de operación) } \\
\text { Penetración de capital } \\
\text { extranjero (\%) } \\
\text { Especialización }\end{array}$ & $\begin{array}{c}240 \\
10 \\
17 \\
\text { sectores } \\
\text { maduros } \\
(80 \% \text { empleo })\end{array}$ & $\begin{array}{c}150 \\
14 \\
6 \\
\text { sectores } \\
\text { maduros } \\
(65 \% \text { empleo })\end{array}$ \\
\hline $\begin{array}{l}\text { Adquisición } \\
\text { tecnológica }\end{array}$ & $\begin{array}{l}\text { Inversión en maquinaria } \\
\text { y equipo ( } \% \text { de las ventas) } \\
\text { Pagos por transferencia } \\
\text { de tecnología ( } \% \text { de las } \\
\text { ventas) }\end{array}$ & 0.8 & 0.6 \\
\hline $\begin{array}{l}\text { Esfuerzo } \\
\text { tecnológico }\end{array}$ & $\begin{array}{l}\text { Propensión de la actividad } \\
\text { de I+D (\% de la población) } \\
\text { Intensidad del gasto en } \\
\text { I+D (\% de las ventas) } \\
\text { Participación de ingenieros } \\
\text { en el empleo (\%) } \\
\text { Diseño, ingeniería y } \\
\text { preproducción (\% del } \\
\text { gasto innovador) } \\
\text { Mercadotecnia de nuevos } \\
\text { productos (\% del gasto } \\
\text { innovador) // (\% de las } \\
\text { ventas) } \\
\text { Capacitación asociada a } \\
\text { productos nuevos (\% del } \\
\text { gasto innovador) }\end{array}$ & $6(1.6 \%)$ & $10(0.2 \%)$ \\
\hline $\begin{array}{l}\text { Resultado } \\
\text { innovador }\end{array}$ & $\begin{array}{l}\text { Tasa de introducción de } \\
\text { productos nuevos (base } \\
\text { trianual) } \\
\text { Impacto en las ventas } \\
\text { por productos mejorados } \\
\text { (\% en las ventas) }\end{array}$ & 4.3 & 0.9 \\
\hline $\begin{array}{l}\text { Conducta } \\
\text { exportadora }\end{array}$ & $\begin{array}{l}\text { Propensión exportadora } \\
\text { ( } \% \text { de la población) }\end{array}$ & 37.5 & 32 \\
\hline
\end{tabular}

Fuente: Elaboración propia a partir de CEESP (1996), Conacyt (1999, 2003), EIA, (2003), ENESTyc $(1995,1999)$ y Esidetvineg (Concyteg-INEGI, 2000). 
Hasta aquí, la evidencia proporciona los resultados esperados; sin embargo, el conjunto de establecimientos estudiados son más longevos y duplican el esfuerzo en adquisición de tecnología dura (maquinaria y equipo).

Estas son las dimensiones directamente comparables; no obstante, de la información descrita líneas arriba pueden inferirse algunas diferencias en otros atributos que se enlistan a continuación:

- Si bien los sectores tradicionales contribuyen con la mayor parte del empleo y las ventas, tanto en el país como en la región analizada, en Guanajuato tienen una mayor importancia relativa los sectores más modernos.

- Parece que existe una interacción más intensa con proveedores de servicios tecnológicos, tanto para los oferentes en el mercado como para otros actores institucionales, tales como la infraestructura pública, las universidades y los centros de investigación. También parece razonable que el sector productivo emplee a un mayor número de ingenieros.

- Entre los gastos dedicados a otras actividades innovadoras, la participación relativa del diseño triplica la proporción nacional. En cuanto a la dedicación de recursos a la mercadotecnia para productos nuevos, parece mayor la importancia en Guanajuato, aunque en términos del gasto total -en publicidad y propaganda respecto a las ventas- es bastante verosímil que el esfuerzo sea menor. La capacitación vinculada a la introducción de productos nuevos parece ser la actividad que menos énfasis tiene en los gastos innovadores, aunque entre las empresas de la región analizada queda aún más debilitada su importancia relativa.

- Las empresas estudiadas tienden a descansar en ingresos obtenidos de una sola fuente de productos. Esto nos lleva a pensar que se orientan hacia la producción de productos estandarizados y que la ventaja competitiva se basa en la reducción de costes o en la adopción de sistemas flexibles que mejoren la coordinación.

\section{Perfiles de la conducta tecnológica}

Hemos descrito las diferencias más evidentes del conjunto de establecimientos manufactureros sujetos de estudio. Sin embargo, se basan en un perfil medio de empresa -agente "representativo"-, con lo cual se restringe la heterogeneidad que se encuen- 
tra en una población de empresas. Una alternativa para explorar la versatilidad de la descripción es probarla frente a empresas de diferentes características. El análisis detallado del caso de estudio permite sugerir perfiles de la conducta tecnológica asociados con un tipo de empresa específica controlando por tamaño, edad, propiedad y sector del cambio tecnológico. Encontramos algunos casos interesantes por un perfil más asentado en atributos característicos de la empresa media nacional, o bien por sus rasgos más acordes con el establecimiento del caso de estudio. En cualquier caso son empresas que presentan un desempeño superior a la media poblacional o bien concentran los recursos desplegados en toda la muestra (véase la tabla 2).

\subsection{Control por tamaño}

- Las empresas pequeñas destinan, respecto a sus ventas, mayores gastos a la adquisición de tecnologías no incorporadas, a las actividades de $\mathrm{I}+\mathrm{D}$ y a la capacitación relativa a la introducción de productos nuevos. También la tasa de introducción de productos nuevos es mayor, al igual que el impacto en las ventas por este tipo de productos. Este perfil estaría asociado con las características en las que los establecimientos nacionales muestran ventajas respecto al caso de estudio.

- Salvo en los recursos destinados a capacitación, todos los atributos anteriores están concentrados en este tipo de empresa.

- Además superan a la empresa guanajuatense media en el número de usuarios de servicios tecnológicos, la participación de ingenieros en la plantilla de empleados y la intensidad de ventas no diversificadas.

- Las empresas medianas tienen un perfil similar al de las empresas pequeñas, salvo que no concentran ningún atributo. A diferencia de las pequeñas, su esfuerzo es mayor en la adquisición de maquinaria y equipo y no en $\mathrm{I}+\mathrm{D}$, se desempeñan mejor movilizando sus recursos hacia el diseño y no con una mayor proporción de ingenieros ni tampoco dedicando recursos a la capacitación.

- Las empresas grandes, tal como el perfil de la empresa nacional, tienen mayor participación de capital extranjero, son más propensas a realizar I+D, destinan recursos a capacita- 
Tabla 2

Perfiles tecnológicos de empresas manufactureras: distribución y eficiencia de variables según tamaño, edad, propiedad y sector tecnológico

\begin{tabular}{|c|c|c|c|c|c|c|c|c|c|c|c|c|c|c|}
\hline \multirow[b]{2}{*}{ Variables } & \multicolumn{3}{|c|}{ Tamaño } & \multirow[b]{2}{*}{ G } & \multicolumn{3}{|c|}{ Edad } & \multicolumn{2}{|c|}{ Propiedad } & \multicolumn{5}{|c|}{ Sector } \\
\hline & $\mathrm{Mi}$ & $P$ & M & & $\mathrm{J}$ & A & V & IND GN & ETN & J TRAD & PROV & $V$ ESP & IE & $\mathrm{BC}$ \\
\hline Población & $\mathrm{C}$ & $\mathrm{C}$ & $\mathrm{C}$ & & & & $\mathrm{C}$ & $\mathrm{C}$ & & $\mathrm{C}$ & & & & \\
\hline Tamaño & & & & $\mathrm{C}$ & & & $\mathrm{E}$ & C & $\mathrm{E}$ & $\mathrm{C}$ & & & $\mathrm{E}$ & \\
\hline Ventas & $\mathrm{C}$ & $\mathrm{C}$ & $\mathrm{C}$ & & & & $\mathrm{C}$ & C & & C & & & & \\
\hline Edad & & & & $\mathrm{E}$ & & & & $\mathrm{E}$ & & & & & $\mathrm{E}$ & \\
\hline Cap. ext. & & & & $\mathrm{E}$ & & & & & & & 0 & E & E & \\
\hline Maq. y eq. & $\mathrm{E}$ & & $\mathrm{E}$ & $\mathrm{C}$ & & & & $\mathrm{E}$ & & & $\mathrm{E}$ & $\mathrm{E}$ & & \\
\hline Tec. no incor. & & $\mathrm{E} / \mathrm{C}$ & $\mathrm{E}$ & & $\mathrm{E}$ & $\mathrm{E}$ & & & & $\mathrm{E}$ & & $\mathrm{C}$ & & \\
\hline Serv. téc. & & E & $\mathrm{E}$ & & & $\mathrm{E}$ & & & & & & & & \\
\hline Prop. I+D & & & & $\mathrm{E}$ & & $\mathrm{E}$ & $\mathrm{E}$ & & & & & E & $\mathrm{E}$ & E \\
\hline Int. I+D & & $\mathrm{E} / \mathrm{C}$ & & $\mathrm{C}$ & & $\mathrm{E}$ & $\mathrm{C}$ & $\mathrm{C}$ & & & 0 & $\mathrm{E} / \mathrm{C}$ & & E \\
\hline Ingenieros & $\mathrm{E}$ & $\mathrm{E}$ & & $\mathrm{C}$ & $\mathrm{E}$ & & $\mathrm{E} / \mathrm{C}$ & $\mathrm{C}$ & & C & & $\mathrm{E}$ & $\mathrm{E} / \mathrm{C}$ & \\
\hline Diseño & & & $\mathrm{E}$ & & $\mathrm{E}$ & & & $\mathrm{C}$ & $\mathrm{E}$ & C & 0 & $\mathrm{E}$ & & $\mathrm{C}$ \\
\hline Mkting. & & & & & & $\mathrm{E}$ & & $\mathrm{C}$ & $\mathrm{E}$ & $\mathrm{C}$ & 0 & $\mathrm{E} / \mathrm{C}$ & 0 & 0 \\
\hline Formación & & E & & $\mathrm{E} / \mathrm{C}$ & & & & & & $\mathrm{C}$ & 0 & & $\mathrm{E} / \mathrm{C}$ & \\
\hline Prod. mej. & & & & $\mathrm{E} / \mathrm{C}$ & C & $\mathrm{E}$ & & $\mathrm{E}$ & $\mathrm{E}$ & $\mathrm{E} / \mathrm{C}$ & & & $\mathrm{E} / \mathrm{C}$ & \\
\hline Nuevos prod. & & $\mathrm{E} / \mathrm{C}$ & $\mathrm{E}$ & & & & & & E & $\mathrm{E}$ & & & & \\
\hline No diversif. & & E & $\mathrm{E}$ & $\mathrm{C}$ & & & & $\mathrm{E}$ & & E & & & & \\
\hline
\end{tabular}

Donde:

Mi = Microestablecimientos (1-30), P = Pequeños establecimientos (31-100 empleados), $\mathrm{M}=$ Medianos establecimientos (101-250) y $\mathrm{G}=$ Grandes establecimientos (más de 250 empleados).

$\mathrm{J}=$ Establecimientos jóvenes (nacidos después del TLCAN, desde 1994), A = Establecimientos adultos (nacidos en el periodo de la transición hacia la apertura, 1985-1993), $\mathrm{V}=$ Establecimientos viejos (nacidos antes o durante el periodo de la industrialización basada en la sustitución de importaciones, antes de 1985).

IND = Establecimientos independientes, $\mathrm{GN}=$ Establecimientos de grupos nacionales, ETN = Establecimientos de empresas transnacionales.

TRAD $=$ Bienes de consumo tradicional, PROV $=$ Proveedores tradicionales de bienes intermedios, ESP = Proveedores especializados en bienes intermedios y de maquinaria y equipo, $\mathrm{IE}=$ Intensivos en escala y ensamblaje, $\mathrm{BC}=$ Basados en la ciencia.

$\mathrm{E}=$ Mayor eficiencia en su subgrupo que la media poblacional, $\mathrm{C}=$ Concentran los recursos de la población, $0=$ Tienden a participar marginalmente.

Fuente: Elaboración propia a partir de la Esidetvineg (Concyteg-INEGI, 2000).

ción en mayor medida que la media, y en sus ventas los productos mejorados tienen mayor preponderancia.

- Además comparten la característica de la mayor longevidad con la empresa promedio guanajuatense.

- Estas empresas concentran el capital extranjero, los recursos dedicados a la compra de maquinaria y equipo, la I+D y la capacitación, así como la demanda de ingenieros y las ventas provenientes de un solo producto o de bienes mejorados. 


\subsection{Control por edad}

- Las empresas adultas destinan mayores gastos a la adquisición de tecnología y a las actividades de I+D, por las que tienen una propensión mayor. El impacto por la venta de productos mejorados es mayor.

- Superan a la empresa media del caso de estudio en el número de usuarios de servicios tecnológicos y en la intensidad de los gastos en el lanzamiento de productos nuevos.

- Las empresas jóvenes concentran las ventas por productos mejorados, mientras que las viejas, las ventas por productos nuevos, además de los gastos en I+D y la demanda de ingenieros.

\subsection{Control por propiedad}

- Las empresas filiales de grupos transnacionales son preponderantemente grandes, presentan la mayor tasa de introducción de productos nuevos y tienen la mejor marca por ventas de productos mejorados.

- Gastan mayores recursos en diseño, ingeniería y preproducción respecto a sus ventas, como también en el lanzamiento de nuevos productos, lo cual está acorde con la jerarquía mostrada por estas variables para el caso de Guanajuato.

- Las empresas subsidiarias de grupos nacionales son más longevas y sus ventas provenientes de un solo producto o de bienes mejorados tienen mayor impacto.

- Las empresas independientes gastan, proporcionalmente, mayores recursos en la adquisición de maquinaria y equipo, y concentran los gastos en $\mathrm{I}+\mathrm{D}$, diseño y mercadotecnia de productos nuevos, además de la demanda de personal ingeniero.

\subsection{Control por sector}

- Las empresas encuadradas entre los productores de bienes de consumo tradicional dedican mayores gastos a la adquisición de tecnologías no incorporadas y su tasa de introducción de productos nuevos es mayor, al igual que el impacto en las ventas de productos tanto nuevos como mejorados. 
- En el ámbito nacional, este perfil estaría asociado a las características de algunas actividades más dinámicas de este sector, tales como alimentos -en el gasto en tecnologías no incorporadas-, muebles y otras manufacturas -en las ventas por productos nuevos-, y madera, papel, imprenta y editoriales -en el impacto por producto mejorados-. Sin embargo, para el estudio de caso la única actividad importante entre las anteriores es la de alimentos; hay otras subestimadas en el caso nacional pero importantes en el sector guanajuatense de productores tradicionales, como el cuero, el calzado y la confección.

- Además superan a la empresa media de Guanajuato en la proporción de usuarios de servicios tecnológicos y la intensidad de ventas no diversificadas.

- Diferencias dramáticas se encuentran en el sector de proveedores tradicionales, pues el caso nacional está copado por grandes empresas, en particular corporativos nacionales en minerales no metálicos y con alguna presencia extranjera en metales básicos, que despliegan importantes recursos para $\mathrm{I}+\mathrm{D}$, diseño, tecnología no incorporada y publicidad, mientras que para Guanajuato se trata de pequeños fabricantes de productos metálicos cuyo principal atributo tecnológico es la adquisición de maquinaria y equipo.

- El perfil que se dibuja de las empresas proveedoras especializadas de bienes intermedios maquinaria y equipo es el de empresas con penetración de capital importante con alta propensión relativa a realizar I+D además de dedicar los mayores gastos a esa área.

- Al hacer la comparativa nacional, estas características son propias de las actividades constituyentes de este patrón tecnológico, tales como hule y plásticos, además de maquinaria y equipo.

- El ámbito de Guanajuato presenta características que son también compartidas por el perfil nacional, tales como la intensidad del gasto en maquinaria y equipo -elevado en la elaboración de hule y plástico en el país-, la intensidad en el uso de ingenieros e ingentes recursos dedicados a la mercadotecnia. La única diferencia hallada es que mientras en el ámbito nacional se demandan tecnologías no incorporadas, en el estatal se requiere diseño, ingeniería y preproducción. 
- Sin embargo, este tipo de empresa concentra los recursos manufactureros destinados a tecnologías no incorporadas, además de los relativos a I+D y mercadotecnia de nuevos productos.

- Las empresas dominadas por el patrón intensivo en escala y ensamblaje son las más grandes y mayormente penetradas por capital extranjero. Presentan una propensión mayor a realizar actividades de I+D, gastan más en capacitación y el impacto en sus ventas de productos mejorados también es mayor.

- La descripción anterior guarda una excelente correspondencia con el perfil nacional. El contexto de Guanajuato presenta atributos que son también compartidos por la caracterización nacional de la industria automotriz y el sector de maquinaria y equipo eléctrico y electrónico, tales como el elevado gasto en la adquisición de tecnología dura y la intensa demanda de ingenieros. La única diferencia hallada es que mientras en el ámbito nacional se demandan importantes gastos en mercadotecnia, publicidad y propaganda, para las empresas de nuestro estudio de caso el despliegue de gastos es marginal.

- Las empresas clasificadas en el sector intensivo en ciencia revelan un perfil semejante en cuanto a la empresa media guanajuatense, ya que destacan en dos atributos distintivos del caso estatal: la I+D -tanto en la propensión como en la intensidad- y el impacto en la ventas por productos mejorados. Además concentran los gastos de diseño, ingeniería y preproducción y las ventas por productos mejorados. Contrario al caso nacional, no se destaca en la intensidad del gasto destinado a la adquisición de maquinaria y equipo, y la dedicación de recursos a la mercadotecnia es marginal.

\section{Conclusiones y reflexiones sobre las diferencias en la conducta tecnológica}

Queremos destacar los atributos de desempeño superior de los establecimientos objeto de estudio con la intuición de que están asociados con una ventaja competitiva, aunque sin establecer aún si es en el mercado interno o en el de exportación. De acuerdo con la teoría estratégica de la empresa, se presupone que las variables expresivas de la conducta tecnológica coadyuvan al desarrollo y 
explotación de ventajas específicas a la empresa tanto en los mercados nacionales como en los de exportación (Porter, 1980 y 1985).

Entre los atributos estudiados se destaca el tamaño como un factor potencialmente crítico para contribuir a esta ventaja, lo cual se refuerza con el papel que ese atributo parece jugar, de acuerdo con la literatura analizada para el caso mexicano, en las ganancias de productividad. Estos estudios revelan que, además del tamaño, la productividad se asocia con la participación de capital extranjero, la explotación de economías de escala relativas a la incorporación de capital fijo y la participación más intensiva del capital humano.

En nuestro estudio de caso puede haber distorsiones por el menor tamaño medio de los establecimientos y la menor penetración de capital, aunque es posible que se compensen por la mayor tasa de incorporación de maquinaria y equipo y la aparente explotación más intensiva del capital humano técnico.

Otra variable donde la empresa guanajuatense media presenta un mejor desempeño que su contraparte nacional es en los años de experiencia. Parece que existe una correlación entre la experiencia productiva y la expansión del tamaño, en los dos ámbitos, aunque no podemos precisar si es estadísticamente comprobable, además de si esto se expresa en una mayor productividad. En todo caso, en nuestra población de empresas de Guanajuato se encuentra que las más longevas pertenecen a los grupos nacionales y que su tamaño medio es grande. Estos grupos, de acuerdo con la literatura del contexto mexicano, se fortalecieron durante la etapa de sustitución de importaciones, y ahora, junto con el sector maquilador, son la punta de lanza de la expansión exportadora de México. Ciertamente su número es pequeño en la muestra y no parece que las variables tecnológicas de la empresa media se vean muy afectadas con su contribución, además de que los corporativos presentan sesgo de localización hacia otros estados de la república con mayores efectos de aglomeración. También la evidencia apunta a que la senda de expansión estuvo basada en cambios organizacionales y estrategias financieras, las cuales rebasan el marco de nuestro estudio.

Es en el desempeño en la modernización tecnológica -aproximada por el gasto en maquinaria y equipo- y la participación de capital humano técnico donde Guanajuato parece tener una ventaja respecto al caso nacional. Si persiste en el plano regional la relación detectada en el ámbito nacional de asociar la adquisición de maquinaria y equipo con aumentos en la productividad o a la 
mejora de la calidad de los productos, es posible que la compra de este tipo de bienes afecte la ventaja competitiva de las empresas. El primer caso podría revelarse en el sector intensivo en escala, y el segundo, en el sector de proveedores especializados.

Los ingenieros parecen ser la fuente más relevante de información tecnológica y el medio por el cual las empresas aprenden de sus procesos productivos y de incorporación de nueva tecnología. Una participación más intensiva en la mano de obra de estos profesionales en relación con la situación nacional lleva a pensar que esta variable juega un papel fundamental en el despliegue de ventajas competitivas de las empresas de nuestro caso de estudio. Sin embargo, es posible que sus efectos tengan un sesgo sectorial dado que se verifica una importancia relativamente mayor, tanto del país como de Guanajuato, en los sectores intensivo en escala y de proveedores especializados.

Por otra parte, estos sectores parecen asentar sus ventajas de innovación en actividades diferentes de la I+D, en particular en los gastos en diseño. Esta variable también tiene una importancia mayor en el caso de Guanajuato, por lo que dado el mayor 'protagonismo' de los sectores intensivo en escala y de proveedores especializados, se espera que tienda a reforzar la ventaja competitiva basada la incorporación de capital y la intensidad del capital humano técnico.

Además de la ventaja en el abastecimiento externo de tecnología incorporada, consideramos particularmente relevante la aparente mayor interacción con proveedores de servicios tecnológicos. En el caso mexicano, las empresas se encuentran seriamente aisladas y desarticuladas, no sólo tecnológicamente sino también en la cadena productiva, por lo que la contribución de estos servicios puede fomentar la interacción y ser vehículo de mejores prácticas que tiendan a aumentar el valor agregado de las actividades. Cabe destacar que ni para el caso mexicano ni para el de Guanajuato estos servicios se concentran en los sectores más modernos sino en los tradicionales, tanto de bienes de consumo final como de proveedores. Mientras que en el primero existe mayor demanda por los servicios de consultoría, marketing y gestión de licencias y marcas, en el segundo se requieren servicios de normalización y control de calidad. Si bien estos servicios son muy heterogéneos, es importante destacar que también lo son los proveedores, entre los que encontramos transacciones de mercado con empresas y no de mercado con otros agentes, tales como universidades y centros de investigación. 
Se requieren servicios más elaborados de capacitación, mercadotecnia e I+D como se muestra en la débil demanda detectada en otros sectores productivos más modernos. Aunque es cierto que estos sectores dedican escasos recursos a estas actividades; esto es, no se tiene un suficiente desarrollo de estas fuentes internas de ventaja competitiva. En estas dimensiones es que Guanajuato presenta una gran desventaja respecto a México, la cual tiende a agudizarse debido a su aparente correlación con la escala, que, recordemos, es menor para los establecimientos de nuestro estudio de caso. Pensamos que aun con el largo camino por recorrer en la incipiente y evanescente actividad en estos campos, los montos registrados pueden discriminar entre las empresas exportadoras y no exportadoras.

Estas debilidades también parecen pasar factura a la política de productos. De la revisión del caso mexicano y los propios cálculos para el de Guanajuato, se corrobora que el impacto en las ventas por productos mejorados en ambos casos es mayor que la contribución por los productos nuevos. Éstos se concentran en los productores tradicionales, lo cual refleja, quizá, novedad no estrictamente tecnológica sino estética o marginal en la funcionalidad. Si bien en el caso nacional las mayores tasas de introducción se encuentran en empresas grandes, lo cual podría indicar una genuina novedad tecnológica, para el caso de Guanajuato es entre las pymes, con lo cual reforzamos que la novedad es aparente en nuestro estudio de caso.

Sectorialmente, entre los productores tradicionales se concentran los productos nuevos, las ventas por productos mejorados y los mejores desempeños en la tasa de introducción de productos nuevos, así como el impacto de los mejorados sobre las ventas. En la esfera nacional parece tener mayor relevancia el sector de proveedores tradicionales, y en ambos casos de estudio, existe alguna contribución significativa de los sectores de proveedores especializados y de los intensivos en escala y ciencia. De hecho, para el caso de Guanajuato sobresale el pobre desempeño competitivo del sector intensivo en escala, en variables tanto de adquisición tecnológica como de dinamismo innovador. En todo caso se sugiere controlar por el sector para determinar diferencias significativas entre conductas exportadoras en el ámbito del resultado innovador.

En lo que se refiere a las ventas no diversificadas, no es mucha la información que poseemos. Sin embargo, si se hace una lectura conjunta de acuerdo con la novedad del producto, pueden encon- 
trarse diferencias entre empresas que aparentemente sustentan su competitividad en el mismo factor. Así, es en la propiedad donde se ve una competencia diferente en la capacidad de desarrollo de productos, pues mientras las empresas subsidiarias, tanto nacionales como extranjeras, tienen desempeños superiores a la media en las ventas por productos mejorados, las empresas de grupos nacionales tienen un desempeño superior y menos diversificación, y las empresas transnacionales se cobran mejor en las ventas más diversificadas. Un ejemplo es mejor que ninguno, pero vale con tal de mostrar el potencial discriminante de las ventas no diversificadas en la obtención de ventajas competitivas.

Finalmente quisiéramos comentar dos aspectos relevantes. Hay sectores con débiles (o nulos) esfuerzos en gastos de mercadotecnia: los proveedores tradicionales, los intensivos en escala y los basados en ciencia. Entonces, el marketing es una debilidad por subsanar en el caso de Guanajuato, aunque parece endémico de México. Y dado que la escala juega un papel importante, de acuerdo con los estudios de establecimientos con mayor productividad, se espera que las empresas que no tengan un sesgo hacia el tamaño medio y grande (por ejemplo, los establecimientos jóvenes, independientes, proveedores tradicionales y especializados, así como los basados en ciencia) quizá tengan problemas de economías de escala para expandir su potencial competitivo allende las fronteras.

\section{Anexo}

El marco muestral de la Encuesta sobre investigación y desarrollo experimental, vinculación, tecnología e innovación en el estado de Guanajuato (Esidetvineg) 1999 se basa en un conjunto de empresas ubicadas en el estado de Guanajuato al cual le corresponde $70 \%$ del empleo manufacturero. Además de su relevancia económica, cabe destacar que representa al conjunto de empresas 'objetivo' de las políticas industriales; esto es, las líderes modélicas, las participantes en su formulación, las usufructuarias y las agrupadas en gremio. La técnica de muestreo es aleatoria, estratificada por sector de actividad económica agregada a dos dígitos y tamaño de empresa. 


\section{Representatividad de la encuesta}

\begin{tabular}{|c|c|c|c|c|c|}
\hline \multirow[t]{2}{*}{ Sectores manufactureros } & \multicolumn{2}{|c|}{ Marco muestral } & \multicolumn{2}{|l|}{ Muestra } & \multirow{2}{*}{$\begin{array}{c}\text { Error } \\
\text { Muestra }\end{array}$} \\
\hline & Frecuencia & $\%$ & Frecuencia & $\%$ & \\
\hline Alimentos, bebidas y tabaco & 120 & 11.04 & 75 & 19.23 & $2.0 \%$ \\
\hline Textiles, pieles y cuero & 349 & 32.11 & 108 & 27.69 & $3.2 \%$ \\
\hline $\begin{array}{l}\text { Madera, papel, imprenta y } \\
\text { publicaciones }\end{array}$ & 30 & 2.76 & 18 & 4.62 & $4.3 \%$ \\
\hline $\begin{array}{l}\text { Carbón, petróleo, energía } \\
\text { nuclear, químicos y productos } \\
\text { de caucho y plástico }\end{array}$ & 259 & 23.83 & 81 & 20.77 & $3.7 \%$ \\
\hline $\begin{array}{l}\text { Productos minerales no } \\
\text { metálicos }\end{array}$ & 11 & 1.01 & 11 & 2.82 & $0.0 \%$ \\
\hline Metales básicos & 17 & 1.56 & 7 & 1.79 & $10.1 \%$ \\
\hline $\begin{array}{l}\text { Productos fabricados de } \\
\text { metal }\end{array}$ & 44 & 4.05 & 13 & 3.33 & $9.6 \%$ \\
\hline $\begin{array}{l}\text { Maquinaria, equipo, } \\
\text { instrumentos y equipo de } \\
\text { transporte }\end{array}$ & 244 & 22.45 & 70 & 17.95 & $4.2 \%$ \\
\hline Muebles y otras manufacturas & 13 & 1.20 & 7 & 1.79 & $7.8 \%$ \\
\hline Total & 1087 & 100 & 390 & 100 & $1.5 \%$ \\
\hline
\end{tabular}

Fuente: Elaboración propia con base en la Esidetvineg (Concyteg-INEGI, 2000).

El diseño de la encuesta sigue las recomendaciones internacionales del Manual de Oslo para recolectar e interpretar los datos sobre innovación tecnológica en las empresas. Esta concepción de las actividades y resultados innovadores en las empresas sigue de cerca las propuestas de la economía de la innovación sustentadas en los trabajos de Chris Freeman, Richard Nelson y Sydney Winter; Keith Pavitt, Giovanni Dosi, Daniele Archibugi y Bengt-Åke Lundvall, entre otros. Las encuestas han sido aplicadas sistemáticamente en la Unión Europea -Community Innovation Survey I, II y III- y en algunos países de la Organización para la Cooperación y el Desarrollo Económico y América Latina (países asociados a la Red Iberoamericana de Indicadores de Ciencia y Tecnología, RICyT).

En el cuestionario, además de los datos generales de cada empresa y algunos atributos básicos de su operación, se enfatizan los gastos en actividades conducentes a la introducción de nuevos productos tales como investigación y desarrollo, diseño y preproducción, lanzamiento y capacitación. Otra actividad importante es el gasto en la adquisición de tecnología, tanto en su vertiente incorporada como en la no incorporada. Los resultados innovadores se proyectan sobre la cartera de productos en sus aspectos de novedad y de mejora. También se analizan las actitudes respecto a los métodos de apropiación y las evaluaciones de obstáculos e incentivos para la innovación. En nuestra 


\section{Cuestionario dirigido al sector productivo}

\begin{tabular}{|c|c|c|}
\hline Grupo de variables & Ejemplos de variables/subgrupos de variables & Tipo de variables \\
\hline I. Datos generales & $\begin{array}{l}\text { Años de operación, giro de la empresa, } \\
\text { principales productos, naturaleza del capital, } \\
\text { ventas anuales, mercados, personal promedio } \\
\text { anual }\end{array}$ & $\begin{array}{l}\text { Binaria, } \\
\text { Métrica, } \\
\text { Nominal }\end{array}$ \\
\hline $\begin{array}{l}\text { II. Investigación y } \\
\text { desarrollo } \\
\text { experimental }\end{array}$ & $\begin{array}{l}\text { Actividades externas e internas, gastos, } \\
\text { número de personas dedicadas, unidad } \\
\text { formal, principales objetivos, convenios, } \\
\text { tipo de institución }\end{array}$ & $\begin{array}{l}\text { Binaria, } \\
\text { Métrica, } \\
\text { Ordinal }\end{array}$ \\
\hline III. Tecnología & $\begin{array}{l}\text { Adquisición de maquinaria equipo, tipo } \\
\text { de maquinaria, efectos en la empresa, } \\
\text { adquisición/transferencia de tecnología, tipo } \\
\text { de proveedor, frecuencia de utilización de } \\
\text { método de provisión, cambios en la } \\
\text { organización }\end{array}$ & $\begin{array}{l}\text { Binaria, } \\
\text { Métrica, } \\
\text { Ordinal }\end{array}$ \\
\hline IV. Innovación & $\begin{array}{l}\text { Introducción de productos nuevos, alcance } \\
\text { de novedad, impacto en las ventas, gastos } \\
\text { por tipo de actividad, unidad de ingeniería, } \\
\text { número de personas dedicadas a ingeniería, } \\
\text { importancia de fuentes de información } \\
\text { (internas/externas), fuentes de } \\
\text { financiamiento, patentes (solicitadas/ } \\
\text { concedidas, país/extranjero),valoración de } \\
\text { métodos de apropiabilidad, objetivos de } \\
\text { la innovación, motivaciones y obstáculos. } \\
\text { ayudas públicas }\end{array}$ & $\begin{array}{l}\text { Binaria, } \\
\text { Métrica, } \\
\text { Ordinal }\end{array}$ \\
\hline
\end{tabular}

Fuente: Elaboración propia con base en la Esidetvineg (Concyteg-INEGI, 2000).

aproximación sólo explotaremos las variables referidas a los recursos y resultados.

En lo que atañe al trabajo de campo, éste fue realizado por el propio personal del INEGI, por lo que se siguen estándares internacionales para la recogida y validación de la información. La muestra se compone de 390 establecimientos, con un error muestral del $\pm 1.5 \%$ y con un nivel de confianza de $95 \%$. Dado que se conoce la probabilidad de selección de cada elemento sustraído del marco muestral, los resultados pueden expandirse para los 1,087 establecimientos del universo original.

\section{Bibliografía}

Álvarez, Jesús (1995), "Experiencias de vínculos entre instituciones de educación superior, centros de investigación y desarrollo tecnológico y el sector industrial en México" en Pablo Mulás del Pozo (coord.), Aspectos tecnológicos de la modernización industrial de México, Fondo de Cul- 
tura Económica-Academia de la Investigación CientíficaAcademia Nacional de Ingeniería, México, pp. 296-316.

ANUIES (Asociación Nacional de Universidades e Instituciones de Educación Superior) (1996), Catálogos de casos. Vinculación entre los sectores académico y productivo en México, ANUIES, México.

Archibugi, Daniele, Sergio Cesaratto y Giorgio Sirilli (1991), "Sources of Innnovative Activities and Industrial Organization in Italy", Research Policy, 20 (4): 283-298.

Arvanitis, Rigas y Daniel Villavicencio (1998), “Technological Learning and Innovation in the Mexican Chemical Industry: An Exercise in Taxonomy", Science, Technology and Society, 3 (2), http://perso.option-service.fr/rigas/papiers/ sts/RADV.html.

Barajas Escamilla, María del Rocío (2000), Global Production Networks in an Electronics Industry: The Case of the Tijuana-San Diego Binational Region, Ph D. dissertation, University of California, Irvine.

Blomström, Magnus y Edward Wolff (1994), "Multinational Corporations and Productivity Convergence in Mexico", en William J. Baumol, Richard R. Nelson y Edward Wolff (eds.), Convergence of Productivity: Cross-National, Studies and Historical Evidence, Oxford University Press, Oxford, pp. 263-284.

Brown, Flor y Lilia Domínguez (1999a), "Los determinantes de la productividad manufacturera”, en Flor Brown y Lilia Domínguez (coords.), Productividad: desafío de la industria mexicana, Jus-Universidad Nacional Autónoma de México, México, pp. 15-32.

(1999b), "El perfil tecnológico de las empresas de alta productividad", en Flor Brown y Lilia Domínguez (coords.), Productividad: desafío de la industria mexicana. Editorial Jus-unam, México, pp. 33-60. 
Buesa, Mikel y José Molero (1996), Innovatory Activity in Spanish Firms: Regular versus Ocasional Patterns, ponencia presentada en la International Conference on Management and New Technologies, 12 a 14 de junio, Madrid.

Buitelaar, Rudolf, Ramón Padilla Pérez y Ruth Urrutia (1999), "Industria maquiladora y cambio técnico", Revista de la Cepal, 67: 133-152.

Capdevielle, Mario, Juan Manuel Corona y Carlos Hernández (1998), "Patrones tecnológicos sectoriales en la industria mexicana”, en José Flores Salgado y Carlos Rozo Bernal (comps.), Cambio estructural, educación y bienestar, Universidad Autónoma Metropolitana-Xochimilco, División de Ciencias Sociales y Humanidades, México, pp. 23-50.

Carrillo Viveros, Jorge Héctor (2001), "Maquiladoras de exportación y la formación de empresas mexicanas exitosas", en Enrique Dussel Peters (coord.), Claroscuros. Integración exitosa de las pequeñas y medianas empresas en México, Jus-Comisión Económica para América Latina-Cámara Nacional de la Industria de la Transformación, México, pp. 157-208.

y Alfredo Hualde (1996), "Maquiladoras de tercera generación. El caso de Delphi-Motors”, Espacios. Revista Venezolana de Gestión Tecnológica, 17 (3): 111-134.

Casalet, Monica y Rosalba Casas (1998), Un diagnóstico sobre la vinculación universidad-empresa, ANUIES-Conacyt, México.

Casanueva, Cristina y Alejandro Márquez (2003), Innovación tecnológica, capital humano y desempeño exportador: la industria manufacturera no-maquiladora en México (19891999), ponencia presentada en el x Seminario Latino-Iberoamericano de Gestión Tecnológica ALTEC 2003, 22 al 24 de octubre, México.

Casas, Rosalba (2003), Networks and Interactive Learning among Academic Institutions, Firms and Government: Knowledge-Based Social Capital for Local Development, ponencia presentada en el x Seminario Latino-Iberoamericano de 
Gestión Tecnológica ALTEC 2003, 22 al 24 de octubre, México.

(ed.) (2001), La formación de redes de conocimiento. Una perspectiva regional desde México, Instituto de Investigaciones Sociales, Universidad Nacional Autónoma de México-Anthropos, Barcelona.

, Rebeca de Gortari y María Josefa Santos (2000), “The Building of Knowledge Spaces in México. A Regional Approach to Networking”, Research Policy, 29: 225-241.

CEESP (Centro de Estudios Económicos del Sector Privado) (1996), "Los efectos de la crisis sobre las empresas en el segundo semestre de 1995. Resultados de la Encuesta Semestral del CEESP", Actividad Económica, 189, México, en Enrique Hernández Laos (2000), La competitividad industrial en México, Plaza Valdés Editores-Universidad Autónoma Metropolitana-Iztapalapa, México, p. 301.

Cimoli, Mario (2000) (coord. y ed.), Developing Innovation Systems: Mexico in a Global Context, Continuum International Publishing Group, Londres y Nueva York.

(2001), "Some Notes on Mexican Economic Reforms and their Implications on the Technological and Organizational Learning Paths”, en Gabriela Dutrénit, Celso Garrido y Giovanna Valenti (eds.) Sistema Nacional de Innovación Tecnológica. Temas para el debate en México, Universidad Autónoma Metropolitana, México, pp. 167-194.

Conacyt (Consejo Nacional de Ciencia y Tecnología) (1999, 2003), Encuestas Nacionales de Innovación en el Sector Manufacturero, Conacyt, México.

Concyteg-INegr (Consejo de Ciencia y Tecnología del Estado de Guanajuato-Instituto Nacional de Estadística, Geografía e Informática) (2000), Esidetvineg, Encuesta sobre Investigación y Desarrollo Experimental, Vinculación, Tecnología e Innovación en el Estado de Guanajuato 1999, base de datos. 
Corona, Juan Manuel y Carlos Hernández (1999), "Relación proveedor-usuario y flujos de información tecnológica en la industria mexicana", en José Flores Salgado y Federico Novelo Urdanivia (comps.), Innovación tecnológica y gestión de las organizaciones, División de Ciencias Sociales y Humanidades, Universidad Autónoma MetropolitanaXochimilco, México, pp. 135-164.

Corona Treviño, Leonel (coord.) (1997), Cien empresas innovadoras en México, Miguel Ángel Porrúa-unAm, colecc. Las Ciencias Sociales, México.

Coronado, Martha y Alfredo Tapia (1998), "Vinculación universidad-sector productivo: una visión de estudiantes de nivel superior sobre su formación y participación”, Acta Universitaria, Universidad de Guanajuato, diciembre, 8 (2): 3-14.

De la Garza Toledo, Enrique (coord.) (1998) Modelos de industrialización en México, Universidad Autónoma Metropolitana-Iztapalapa, colecc. csH, México.

Dussel Peters, Enrique (1997), Economía de la polarización. Teoría y evolución del cambio estructural de las manufacturas mexicanas (1988-1996), unAM-Jus, México.

Dutrénit, Gabriela y Mario Capdevielle (1993), “El perfil tecnológico de la industria mexicana y su dinámica innovadora en la década de los ochenta”, El Trimestre Económico, 239: 643-674.

EIA, Encuesta Industrial Anual (2003), INEGI, México.

ENESTYC, Encuesta Nacional de empleo, salarios, tecnología y capacitación en el sector manufacturero (1992, 1995, 1999), INEGI-Secretaría del Trabajo y Previsión Social-Oficina Internacional del Trabajo, México.

Estrada, Salvador (1997), Vínculos entre la Universidad Autónoma Metropolitana y la Industria en Materia de Ingeniería Ambiental, tesis de Maestría en Economía y Gestión del 
Cambio Tecnológico, Universidad Autónoma Metropolitana-unidad Xochimilco, México.

Expansión (1997), “TLC y maquiladoras”, informe especial del 8 de octubre de 1997 , p. 52

Frías Peña, Julio, Christopher O’Brien y E. Aldana Farías (2003), Innovation and Competitiveness through the Design of New Products in Mexican SME's, ponencia presentada en el x Seminario Latino-Iberoamericano de Gestión Tecnológica ALTEC 2003, 22 al 24 de octubre, México.

Gereffi, Gary y Tony Tam (1998), "Industrial Upgrading through Organizational Chains: Dynamics of Rent, Learning and Mobility in the Global Economy", ponencia presentada en el $93^{\text {rd }}$ Annual Meeting of the American Sociological Association, 21 al 25 de agosto, San Francisco, CA.

González-Aréchiga, Bernardo y José C. Ramírez (1989), "Perspectiva estructural de la industria maquiladora", Comercio Exterior, 39 (10): 874-886.

Hernández Laos, Enrique (1985), La productividad y el desarrollo industrial de México, Fondo de Cultura Económica, México.

Hualde, Alfredo (2001), Aprendizaje industrial en la frontera norte de México. La articulación entre el sistema educativo y el sistema productivo maquilador, El Colegio de la Frontera Norte-Plaza y Valdés Editores, México.

INEGI (Instituto Nacional de Estadística Geografía e Informática) (2000), XV Censo Industrial, INEGI, México.

Jaramillo, Hernán, Gustavo Lugones y Mónica Salazar (2001), Normalización de indicadores de innovación tecnológica en América Latina y el Caribe. Manual de Bogotá, OEARICYT-OCYT-CYTED-Colciencias, Santafé de Bogotá. 
Katz, Jorge (1976), Importación de tecnología, aprendizaje e industrialización dependiente, Fondo de Cultura Económica, México.

y Giovanni Stumpo (2001), Regimenes competitivos sectoriales, productividad y competitividad internacional, Serie Desarrollo Productivo, núm. 103, Red de Reestructuración y Competitividad, Cepal.

Lara Rivero, Arturo Ángel (1998), Aprendizaje tecnológico y mercado de trabajo en las maquiladoras japonesas, Universidad Autónoma Metropolitana-Miguel Ángel Porrúa, México.

Laursen, Keld y Valentina Meliciani (2000), “The Importance of Technology-Based Intersectoral Linkages for Market Share Dynamics”, Weltwirtschaftliches Archiv, 136: 702-723.

López Leyva, Santos (2003), "Empresarios e innovación tecnológica en Sinaloa”, Región y Sociedad, xv (27): 179-214.

López-Martínez, Roberto y José Luis Solleiro (1995), “La experiencia reciente de vinculación universidad-empresa en México”, en Centro para la Innovación Tecnológica (CIT), Vinculación universidad-empresa. Compendio sobre gestión de la innovación tecnológica, UD-CIT, UNAM, pp. 1735 .

Luna, M. (ed.) (en prensa), Itinerarios del conocimiento. Formas, dinámicas y contenido. Un enfoque de redes, Instituto de Investigaciones Sociales, UNAM-Anthropos, Barcelona.

MEGCYT, Maestría en Economía y Gestión del Cambio Tecnológico (1994), Evaluación de un macroproyecto de polímeros, Grupo Industrial Resistol, sA, México (mimeo).

Mendoza, Miguel Ángel (1999), “¿Convergencia o divergencia regional de la productividad manufacturera?”, en Flor Brown y Lilia Domínguez (coords.) (1999), Productividad: desafío de la industria mexicana, Jus-unam, México, pp. 79-100. 
Mohnen, Pierre y Pierre Therrien (2003), "How Innovative are Canadian Firms Compared to Some European Firms? A Comparative Look at Innovation Surveys", Technovation, abril, 23 (4): 359-369.

Pacheco Salazar, Víctor Francisco, I. B. Reyes Rojas y Graciela Virginia Mejía Pedrero, (2003), Visión empresarial de la ciencia y la tecnología en el Estado de México. Encuesta de opinión, ponencia presentada en el x Seminario Latino-Iberoamericano de Gestión Tecnológica ALTEC 2003, 22 al 24 de octubre, México.

Pavitt, Keith (1984), "Sectoral Patterns of Technological Change: Towards a Taxonomy and a Theory", Research Policy, 13: 343-474.

Porter, Michael (1980), Competitive Strategy, Free Press, Nueva York.

(1985), Competitive Advantage, Free Press, Nueva York.

Ramírez, José Carlos (1998), La integración de la industria maquiladora a la economía nacional. Un estudio sobre sus modelos de organización y localización, documento de trabajo del CIDE, núm. 101, Centro de Investigación y Docencia Económicas, México.

y Kurt Unger (1996), Las grandes industrias ante la reestructuración: una evaluación de las estrategias competitivas de las empresas líderes en México, documento de trabajo del CIDE, núm. 53, Centro de Investigación y Docencia Económicas, México.

Soru, Ana (1986), "La componente tecnologica e qualitativa nel modello di specializzazione italiano", en Fabricio Onida (comp.), Vincolo estero, struttura industriale e credito all'esportazione, Il Mulino, Bolonia.

Unger, Kurt (2001a), "La globalización del sistema innovativo mexicano", en Gabriela Dutrénit, Celso Garrido y Giovanna Valenti (eds.), Sistema Nacional de Innovación Tec- 
nológica. Temas para el debate en México, Universidad Autónoma Metropolitana, México, pp. 213-226.

(2001b), La innovación tecnológica y la industrialización mexicana: Una aproximación a clusters regionales, documento de trabajo del CIDE, núm. 205, Centro de Investigación y Docencia Económicas, México.

y Viviane Brachet de Márquez (1981), La tecnología en la industria alimentaría mexicana. Diagnóstico y procesos de incorporación, El Colegio de México, México.

y Luz Consuelo Saldaña (1999), "Industrialización y progreso tecnológico: una comparación entre las regiones de México”, Estudios Sociológicos, septiembre-diciembre, XVII (51).

UNIDO (Unites Nations Industrial Development Organization) (2002), Industrial Development Report 2002/2003. Competing through Innovation and Learning, www.unido.org.

Recibido: 2 de marzo de 2005. Aceptado: 18 de julio de 2005.

Salvador Estrada es ingeniero bioquímico industrial, maestro en economía y gestión del cambio tecnológico por la Universidad Autónoma Metropolitana y doctor por la Universidad Autónoma de Madrid (Programa Interuniversitario en Economía y Gestión de la Innovación y Política Tecnológica, Universidades Autónoma, Complutense y Politécnica de Madrid). Experto universitario en estadística para profesionales por la Universidad Complutense de Madrid. Asistente de investigador en el Institut de Recherche pour le Développement, delegación México. Coordinador editorial de la revista Ciencia y Tecnología Guanajuato. Se ha desempeñado como coordinador de estudios y política científica y tecnológica del Consejo de Ciencia y Tecnología del gobierno del estado de Guanajuato. Becario del Consejo Nacional de Ciencia y Tecnología y del Programa de Indicadores de la Ciencia y la Tecnología en la Comunidad de Madrid por el Instituto de Análisis Industrial y Financiero-UCM. Estudiante invitado a la Globelics Academy 2004, Ph.D. School. Director 
gerente del consorcio consultor SOL I+D y asesor académico de la empresa Time Space Technology s.L. Actualmente es profesor investigador del Centro de Investigaciones Humanísticas de la Universidad de Guanajuato. Es autor de diversas publicaciones sobre competitividad e innovación, sociedad de la información, evaluación de proyectos de ciencia y tecnología y vinculación universidad-empresa. 